\title{
LA REFORMA AGRARIA CHILENA
}

Por SERGIO CORREA REYES, Ayudante de Política Económica de la Escuela de Derecho (Universidad de Chilie); Abogado del Ministerio de Agricultura.

SEGUNDA PARTE

PROYECTO DE LEY DE REFORMA AGRARIA

Sumario de la Segunda Parte

FINES DE LA REFORMA AGRARIA

CAUSALES DE EXPROPIACTON

TIERRAS INEXPROPIABLES

FINANCIAMIENTO DE LA REFORMA

INTRODUCCION.

CAPITULO I.

DE LOS OBJETIVOS FUNDAMENTALES QUE PERSIGUE EL PROYECTO DE REFORMA AGRARIA PROPUESTO AL PARLAMENTO.

1.- Fines mencionados en el Mensaje.

II.- Necesidad de una enmienda constitucional.

III.- Legislación de emergencia en materia de división de predios agrícolas.

\section{CAPITULO II.}

\section{DE LAS CAUSALES DE EXPROPIACION.}

I.- Primera cousal: Exceso de superficie.

II.- Segunda causal: Abandono o mala explotación.

III. - Tercera causal: División de predios con posterioridad al 4 de Noviembre de 1964.

IV.- Cuarta causal: Predios rústicos pertenecientes a personas jurídicas. 
V.- Quinta causal: Infracción por los propietarios, a las normas sobre arrendamientos agrícolas.

VI.- Sexta ccrusal: Predios rústicos pertenecientes a comunidades.

VII.- Séptima causal: Predios rústicos ubicados en la zona de aplicación de la ley de propiedad austral.

VIII.- Octava causal: Predios rústicos que se encuentran comprendidos dentro de un área de riego.

IX.- Novencr causal: Predios rústicos que constituyan minifundios.

X.- Décima causal: Predios que sea necesario adquirir para completar un programa de Reforma Agraria.

\section{CAPITULO III.}

\section{I.- TIERRAS INEXPROPIABLES.}

I.- Las tierras que pertenezcan al propietario óptimo hasta un máximo de 320 hectáreas.

II.- Los predios pertenecientes a personas que se comprometan a realizar en ellos un plan de habilitación de suelos y de explotación racional.

III.-Viñas pertenecientes a empresas vitivinícolas integradas.

IV.- Estaciones Experimentales, Centros de capacitación campesina y Centros de docencia agropecuaria o forestal.

V.- La propiedad familiar agrícola.

VI.- Los bosques artificiales y los bosques naturales acogidos a un plan de ordenación; cuando unos u otros estén situados en terrenos de aptitud exclusivamente forestal 0 en terrenos agrícolas no arables.

\section{CAPITULO IV.}

FINANCIAMIENTO DE LA REFORMA AGRARIA.

I.- Significado del costo.

II.- Cálculos del Ministro de Hacienda. 


\section{INTRODUCCION}

El 22 de Noviembre de 1965, el Presidente de la República de Chile, se. ñor Eduardo Frei Montalva, propuso al Parlamento de su país, un Proyecto de Ley destinado a poner en marcha un vasto proceso de ieforma agraria.

Las diversas normas del referido Proyecto hieren muchos intereses por lo que no resulta extraño que aquel harya levantado la más ardiente polémica de que se tenga memoria en las últimas 3 décadas.

Al tiempo de terminarse el presente artículo, quien escribe estas líneas sintió la tentación de reproducir algo de lo mucho que se ha escrito sobre la reforma chilena, en la creencia de que tal procedimiento daría más vida a un debate profundamente humano. Sin embargo, se ha debido abandonar tal propósito por cuanto el espacio no lo permitía ni era posi- ble, por otra parte, insertar textos seleccionados de más de 1.500 artículos de prensa sin omitir más de alguna opinión valiosa.

En reemplazo de algunas citas de lo que expresaron dirigentes estudiantiles; personeros de sociedades agrícolas, de la industria, el comercio y la construcción; líderes campesinos; representantes de los partidos políticos; Parlamentarios y Ministros de Estado; altos dignatarios de la iglesia y simples pero no menos respetables ciudadanos, hemos estimado del caso hacer algunas reflexiones sobre el real significado de la reforma agraria en nuestro país y en América Latina.

Sobre la necesidad o el por qué de la Reforma Agraria en nuestro continente se han escrito muchísimos $\mathrm{y}$ muy bien terminados estudios. Para el autor, sin embargo, nada hary más elocuente que el siguiente cuadro:

\section{DISTRIBUCION DE LAS EXPLOTACIONES AGROPECUARIAS EN AMERICA LATINA (1)}

CUADRO 1.- América Latina: Resumen de la distribución de las explotaciones agropecuarias, por grupos de tamaño, circa 1960.

\begin{tabular}{|c|c|c|c|c|}
\hline \multirow{2}{*}{$\begin{array}{l}\text { Grupos } \\
\text { de tamaño } \\
\text { (Hectáreas) }\end{array}$} & \multicolumn{2}{|c|}{ Explotaciones } & \multicolumn{2}{|c|}{ Superticie } \\
\hline & Número & Porciento & Hectáreas & Porciento \\
\hline $0-20$ & 7.500 .776 & 76.3 & 34.018 .000 & 4.5 \\
\hline $20-100$ & 1.595 .127 & 16.2 & 71.453 .000 & 9.6 \\
\hline $100-1000$ & 634.448 & 6.5 & 177.426 .000 & 23.7 \\
\hline Más de 1000 & 98.706 & 1.0 & 464.964 .000 & 62.2 \\
\hline Total: & 9.829 .057 & 100.0 & 747.591 .000 & 100.0 \\
\hline
\end{tabular}

1) "Reformas Agrarias en la América Latina", edición preparada por Oscar Delgado, Fondo de Cultura Económica, 1965, página 735. 
Cuando uno piensa que el $62 \%$ de la tierra de América Latina se encuentra en poder de menos de 100 mil personas. Cuando se medita en la circunstancia que menos de 100 mil latifundistas poseen una cabida equivalente al $61 / 2$ veces la superficie de Chile. Cuando se sabe que $8 \mathrm{fa}$ milias son dueñas de un millón 300 mil hectáreas vecinas a Buenos Aires, que 1.150 explotaciones detentan casi 6 millones de hectáreas en Uruguay, que 1.611 explotaciones son dueñas de 45 millones de hectóreas en Brasili o que 29.582 propietarios de Co. lombia detentarían 14,5 millones de hectáreas, salta a la vista que la Reforma no sólo es necesaria, sino que resulta un proceso histórico inevitable. Oponerse a ella es como oponerse al caminar del tiempo.

Por fortuna, en nuestro país ya se ha superado la etapa de las discusiones sobre la necesidad de efectuar la Reforma Agraria. Todo el mundo está de acuerdo en que ella debe realizarse. Lo que si se discute es el camino, procedimiento o forma en que ella debe abordarse.

En la primera parte de este trabajo, que publicamos en el $\mathrm{N}^{\mathrm{a}} 13$ de la Revista de Derecho Económico bajo el título de "Antecedentes de la Reforma Agraria", abordamos el estudio de las condiciones que ha presentado la agricultura nacional a través del tiempo y de las circunstancias que han ido distorsionando su estructura hasta hacerla hoy día totalmente inadecuada para el desarrollo económico social de nuestro país. Si quisiéramos definir el estado actual, en pocas palabras, diríamos que en Chile hay escasez de tierra y agua de riego para quienes pueden explotar estos elementos; que la producición agrícola es deff́citaria a causa de su estructura feudal; y que el nivel de vida campesino reclama una urgente atención.

Ahora bien, con estos antecedentes, podemos afirmar que las mínimas exigencias que debe reunir una efectiva Reforma Agraria en Chile son: a) que el proceso de reforma provoque una efectiva redistribución de la propie. dad de la tierra y del uso de las aguars; y b) que el proceso de reforma esté acompañado de otros tantos cambios estructurales en los sistemas de crédito, de comercialización, asistencia técnica, de las condiciones laborales y de seguridad social en el campo, del régimen de tributación crgrícola y de la carpacitación campesina.

Pues bien, el Proyecto de Reforma Agraria, cuyo análisis empezamos en las páginas que siguen, se refiere exclusivamente a la redistribución de los derechos sobre la tierra y del uso de las aguas de riego, por lo que en principio parecería trunco. En el fondo se trata sólo de una apariencia por cuanto la ley 15.020, de 27 de Noviembre de 1962, primera ley chilena de Reforma Agraria, conjuntamente con los 25 decretos con fuerza de ley que la complementan, representan herramientas que requieren ser adecuadas a las nuevas orienta. ciones, que precisan tan sólo de un pulimiento para obtener de ellas sorprendentes resultados en cuanto a cambios estructurales. Nunca nos cansaremos de afirmar que en Chile sobran leyes llenas de buenos propósitos y lo que generalmente falta es voluntad de aplicarlas. Por otra parte, como veremos en el curso de la exposición, la reforma agraria en proyecto se ha ido definiendo en el camino de la realidad y así ha habido necesidad de enviar al Parlamento 
algunas medidas legislativas de emergencia. Por estas razones la Reforma Agraria a que dé origen el proyecto cuyo estudio iniciomos, debe examinarse como un todo orgónico, considerándose en forma paralela el resto de la legislación agropecuaria.

En consideración a que esta Reforma abre un conjunto de posibilidades de alcance insospechado, el autor desea dejar constancia de la situación que Chile ocupa en la actuali. dad en el concierto de naciones Latinoamericanas, $a$ fin de que en unos 10 años más podamos extraer algunas conclusiones sobre cual ha sido el significado de aquella en nuestro país.

En avance demográfico, Chile es todavía un país pequeño pues sus 9 millones de habitantes representan un conjunto esmirriado frente a los 80 millones de Brasil, 40 de México, 22 de Argentina y 17 de Colombia.

No obstante que Chile posee una extensión territorial superior a la de cualquier país europeo, no es menos efectivo que tampoco nuestra tierra podría equipararse a los $81 / 2$ millones de $\mathrm{Km}$. cuadrados de Brasil, ,a los 1,9 millones de México, a los 1,3 millones de Perú, al 1,1 millón de Colombia y Bolivia o a los 0,9 millones de $\mathrm{Km}$. cuadrados de Venezuela.

Nuestro producto nacional bruto, en 1965, de 3.800 millones de dólares es inferior al de México, Brasil, Argentina, Venezuela y Colombia que ha sido de 16.150, 14.175, 10.835, 6.146 y 4.835 millones de dólares, respectivamente Sin embargo, el producto nacional percápita de los chilenos, de 457 dólares por habitante en 1965, es superior todavía al de todos los de. más países latinoamericanos con la sola excepción de Venezuela y Ar- gentina, en donde alcanza a 724 y 508 dólares, respectivamente

Con este preámbulo veamos ahora cuales son los principales objetivos que persigue el Proyecto de ley sobre Reforma Agraria, según el Mensaje del Ejecutivo, los tropiezos constitu. cionales que ha sido menester vencer y la legislación de emergencia que se dictó para evitar que los agricultores, anticipándose a la Reforma, dividieran sus tierras para no caer en alguna de las causales de expropiación.

\section{CAPITULO I.-}

\section{DE LOS OBIETIVOS FUNDA- MENTALES QUE PERSIGUE EL PROYECTO DE REFORMA A GR A RI A PROPUESTO AL PARLAMENTO.}

I.- Fines mencionados en el Mensaje.

II.- Necesidad de una enmienda constitucionol.

III. - Legislación de emergencia en materia de división de predios agrícolas.

\section{I. - FINES MENCIONADOS EN EL MENSAJE.}

En la primera parte de este trabajo, que denomináramos "Antecedentes de la Reforma Agraria", abordamos el estudio de las condiciones que ha presentado la agricultura nacional a través del tiempo y de las circunstancias que han ido distorsionando su estructura hasta hacerla hoy día totalmenmente inadecuada para el desarrollo económico social de nuestro parís.

Somos los primeros en reconocer 
que esta tarea es larga, a veces tediosa, por cuanto la dirección de una obra legislativa resulta más real, tangible, después que la ley ha tenido alguna aplicación y es posible, a esa altura, apreciar la operancia o inoperancia de las fórmulas y sistemas ideados por el legislador para abordar un determinado plan o conjunto de fines. En cambio, cuando se trata de una ley recién promulgada o tan sólo de un proyecto, cual es el caso presente, siempre existe la incertidumbre que un cuerpo legal óptimo se frustre por circunstancias ajenas a su texto, como ser falta de financiamiento en un país crónicamente exhausto de fondos; escasez de técnicos, de expertos o de ejecutivos con visión audaz; o, simplemente desaliento psicológico del sector empresarial que no responde $a$ los estímulos previstos para provocar un aumento de la producción.

En esta segunda parte, sólo nos referiremos a los fines de la Reforma Agraria, a las causales de expropiación de predios rústicos, y a las tierras inexpropiables, que constituyen la porte más sustancial del proyecto de Reforma Agraria. El resto del articulado, que ahora quedará sin comentar, será desmenuzado en otros dos capítulos, que han de aparecer en el curso del presente año en sucesivos números de la Revista de Derecho Económico, de manera que probablemente ha de coincidir la publicación de la Cuarta Parte del trabajo con la publicación de la Ley. Recordemos que el Proyecto lleva ya 6 meses de discusión parlamentaria $y$ que recién ha sorteado el primer trámite constitucional.

Para analizar los fines del Proyecto de Reforma Agraria, nadie más autorizado para hacerlo que S. E. el Presidente de la República, quien en el Mensaje de la iniciativa expresa:
"Al mismo tiempo que realizar el diagnóstico y observar las causas por las cuales es urgente realizar esta reforma agraria, es indispensable definir los objetivos fundamentales que se persiguen can esta iniciativa contenida en el Proyecto de Ley que hoy sometemos a la consideración del Honorable Congreso.

Ellos básicamente son los siguientes:

Primero, incorporar a la propiedad de la tierra miles de familias campesinas que siendo aptas para trabajarla, pueden cumplir con este viejo anhelo de ser dueños de la tierra que trabajan para obtener el mejoramiento personal $Y$ familiar, $Y$ contribuir al progreso de la comunidad nacional.

A través de esta medida se extenderá y perfeccionará el derecho de propiedad, con un sentido social que significa su pleno ejercicio, basado en el respaldo $y$ respeto que nuestra constitución y nuestras leyes garanti$z \propto n$.

Por el contrario, no se pretende con este Proyecto de Ley desconocer, suprimir o lesionar el derecha de propiedard, sino que quiere extenderlo, reforzarlo y perfeccionarlo, sustituyendo un concepto individualista $Y$ excluyente que no permite el pleno aprovechamiento de los recursos naturales y el desarrollo social de los campesinos, por un derecho de propiedad con sentido social que garamtice el uso de esos bienes en un mar$c o$ de dignidad y justicia, con plena realización del bien común.

Como segundo objetivo, se persigue mejorar sustancialmente la situación productiva de nuestra agri. cultura, cumentando las volúmenes básicos de producción e incrementando la productividad en todos sus niveles 
Y factores que componen esta actividad de nuestra economía nacional.

Una reforma agraria que pretendiera alcanzar sólo el mejoramiento social no podría ser catalogada como integral, si no cumpliera además con el propósito fundamental que la $\mathrm{co}$ munidad nacional espera, cual es, de mejorar la situación general de nuestra economía creando $\mathrm{y}$ garantizando condiciones de justicia e igualdad y dignidad en el sector agrario.

Es indispensable que la reforma agraria tenga éxito, aumentando el volumen de producción de nuestra agricultura. Estamos ciertos que esto sucederá y nuestra preocupación se. rá preferentemente para lograr este propósito.

El tercer objetivo fundamental de nuestra reforma agraria es el de realizar una promoción efectiva y auténtica de los campesinos $y$ de sus tamilias, logrando la incorporación de ellos a la comunidad nacional y a la vida social, cultural, cívica $\mathrm{y}$ política de nuestra patria.

Toda reforma agraria es un proceso que nace de la necesidad de redistribuir y reorganizar sectores importantes de la propiedad de la tierra y la forma como ellas son poseídas $y$ trabajadas. Es indispensable para que opere la reforma agraria que se establezcan mecanismos que impidan y desalienten la acumulación de tierra en una sola mano, limitación que debe establecerse sobre bases técnicas adecuadas, de tal modo que, junto con respetar y garantizar el derecho de propiedad para los que hoy día lo ejercitan con un sentido social, permita una redistribución efectiva y conveniente de la propiedad de la tierra.

La propledad debe ser mantenida $y$ respetada, pero socialmente regulada. No puede existir un derecho de propiedad que en la forma que se ejercita lesione el bien común $y$ los derechos de la comunidad. Cuando así sucede, significa que se está quebrando la norma elemental de que el bien común debe primar sobre el derecho individual, $\mathrm{y}$ es indispensable entonces que el Estado reorganice, regule $\mathrm{y}$ redistribuya estos derechos para evitar dicho abuso.

En resumen, al realizar la reforma agraria, perseguimos lograr la transformarión de las estructuras de la agricultura en forma tal, que posibiliten la incorporación de todo el sector rural al desarrollo social, cultural, económico y político de la nación. Esto debe obtenerse mediante la substitución y reordenamiento de los actuales sistemas de propiedad y tenencia de la tierra por otros más justos que tengan por fundamento una redistribución de dicha propiedad, una reglamentación de los sistemas de tenencia y explotación que mediante el complemento del crédito oportuno y adecuado, la asistencia técnica, el mejoramiento de los siste. mas de comercialización y distribución de los productos, mejoramiento acelerado de los niveles culturales de la población campesina y una acción vigorosa de conservación y acrecentamiento de la capacidad de uso de los recursos naturales renovables, a fin de que la tierra constituya para el hombre que la trabaja base de estabilidad económica, fundamento de su progresivo bienestar y garantía de la libertad y dignidad.

\section{II.- NECESIDAD DE UNA ENMIENDA CONSTITUCIONAL PARA ILEE- VAR A CABO LA REFORMA AGRARIA.}

Sumario del punto: 
I.- Inconstitucionalidad del Proyecto.

2.- Vaivenes de dos Reformas Constitucionales.

3.- Garantía del Derecho de Propiedad.

\section{1.-Inconstitucionalidad del Proyecto.}

Conviene recordar, aunque sólo sea para los efectos de la historia del establecimiento de la ley de Reforma Agraria, que lo primero que sostuvieron los sectores contrarios a la reforma fue la inconstitucionalidad de la iniciativa legal.

Fue por esta razón que el Ejecutivo, en las Comisiones de la $\mathrm{H}$. Cámara de Diputados, formuló la indicación, que pará a incorporarse como art. 165 del Proyecto y cuyo texto es el siguiente:

"Art. 165.- Las disposiciones de la presente ley que requieran para su aplicación previa de determinadas disposiciones de la Constitución Política del Estado, entrarón en vigencia una vez publicada la Reforma Constitucional que las haga procedentes".

\section{2.- Vaivenes de dos Reformas Cons- titucionales.}

Debe tenerse presente, también que con antelación al envío del Proyecto de Reforma Agraria, el Ejecutivo había propuesto a la $\mathrm{H}$. Cámara un Proyecto de Reforma a la Cnstitución Política del Estado, el que durante el inicio de la discusión del Proyecto de Reforma Agraria, pasó en segundo trámite constitucional de la H. Cámara al H. Senado. Lo llamaremos Proyecto General.
Planteada la inconstitucionalidad del Proyecto de Reforma Agraria, las fuerzas de aranzada llegaron a un entendimiento político en el H. Senado para desglosar del Proyecto de Reformas a la Constitución, ya aprobado por la Cámara, la referente a la modificarción del artículo $10 \mathrm{~N}$ \% 10, de la actual Carta Fundamental, que se refiere al derecho de propiedad.

En cumplimiento del referido compromiso, el Senado despachó entonces, en primer trámite constitucional, un Proyecto de Reforma a la garantía establecida en el mencionado artículo, lo que políticamente significó me. nos polémica para el Proyecto de Reforma Agraria y un gran revuelo en torno a la función social del derecho de dominio, a la demolición del derecho de propiedad, etc. $A$ este Proyecto le daremos el calificativo de Proyecto Especial.

Posteriormente, este Proyecto Especial de Reforma Constitucional fue adicionado con otras materias por la vía de las indicaciones parlamentarias. Este Proyecto Especial de Reforma Constitucional ha quedado con un artículo único permanente y 3 transitorios. Además de modificaciones al derecho de propiedad, contiene disposiciones que se refieren $\alpha$ la consagración de los Derechos Sociales, a las incompatibilidades parlamentarias $\theta$ inhabilidades, al Plebiscito, y a la creación de la décima circunscripción electoral.

\section{3.- Garantía del Derecho de Propie- dad.}

La forma en que ha quedado redactada esta enmienda al artículo 10 No 10 , es la siguiente:

"Artículo 10.- La Constitución asegura a todos los habitantes de la República: 
"No 10.- El derecho de propiedad en sus diversas especies.

La ley establecerá el modo de adquirir la propiedad, de usar, gozar y disponer de ella y las limitaciones y obligaciones que permitan asegurar su función social y hacerla accesible a todos. La función social de la propiedad comprende cuanto exijan los intereses generales del Estodo, la utilidad y la salubridad pública, el mejor aprovechamiento de las fuentes $y$ energías productivas en el Servicio de la colectividad y la elevación de las condiciones de vida del común de los habitantes.

"El Estado tiene el dominio absoluto, exclusivo, inalienable $\theta$ imprescriptible de todas las minas, de las covaderas, de las depósitos de carbón y de hidrocarburos, con excepción de las pertenencias vigentes, de las arcillas superficiales, $\mathrm{y}$ de las rocas, arenas y demás materiales aplicables directamente a la construcción que se encuentren en terreno de propiedad privada. El Estado puede otorgar concesiones para explorar o para explotar en conformidad a la ley. La ley procurará establecer un sistema de amparo que, resguardando los derechos de los mineros en actividad, permita recuperar para el dominio del Estado las pertenencias inactivas e innecesarias para las que estén en exploración 0 explotación. Ninguna concesión puede otorgarse sobre hidrocarburos líquidos y gaseosos".

A iniciativa del Presidente de la República y cuando el interés de lá comunidad nacional lo exija, la ley podrá reservar al Estado el dominio exclusivo de recursos naturales, bienes de producción u otros, que declare de impartancia preeminente para la vida económica, social o cu!tural del país. El Estado promoverá formas de propiedad comunitaria o social que incorporen a los trabajadores a la gestión y dominio de las empresas y actividades económicas, básicas para el bienestar y desarrollo del país. Propenderá, asimismo, a la conveniente distribución de la propiedad y a la constitución de la propie. dad familiar.

"Nadie puede ser privado de su propiedad sino en vitrud de sentencia judicial o de ley general o especial que autorice la expropiación por causa de utilidad pública o de interés social calificada por el legislador. El expropiado tendrá siempre derecho a indemnización. Las reglas a que deberán sujetarse los Tribunales o la Administración para determinar el monto de la indemnización y las que fijen las condiciones de su pago, serán establecidas equitativamente por la ley en consideración a las necesidades del bien común y a los intereses de los expropiados. La ley determinará el tribunal que conczca de las reclamaciones sobre el monto de la indemnización, el que en todo caso fallará conforme a derecho; la forma de extinguir la obligación de indemnizar, la parte que debrá pagarse de contado, el plazo y condiciones en que se entregará el saldo, si lo hubiere, y las oportunidades y modo en que el expropiador tomará posesión del bien expropiado.

Los preceptos legales que autoricen el pago diferido de la indemnización serán de la exclusiva iniciativa del Presidente de la República y el Congreso no podrá aprobar condiciones de pago más onerosas para el expropiado que las propuestas por aquél.

Cuando se trate de expropiación de predios rústicos, la indemnización será equivalente al avalúo vigente para los efectos de la contribución territorial, más el valor de las mejoras 
que no estuvieren comprendidas en dicho avalúo y podrá pagarse con una parte al contado y el saldo en cuotas en un plazo no superior a treinta años, todo ello en la forma y condiciones que la ley determine.

La ley podrá reservar al dominio nacional de uso público todas las aguas existentes en el territorio nacional y expropiar, para incorporarse a dicho dominio, las que sean de pro. piedad particular. En este caso, los dueños de las aguas expropiadas continuarán usándalas en calidad de concesionarios de un derecho de aprovechamiento y sólo tendrán derecho a indemnización cuando por la extinción total o parcial de ese derecho, sean efectivamente privados del agua suficiente para satisfacer, mediante un uso racional y beneficioso, las mismas necesidades que satisfacían con anterioridad a la extinción.

La pequeña propiedad rústica trabajada por su dueño y la vivienda habitada por su propietario, no podrán ser expropiadas sin previo pago de la indemnización".

\section{Artículo Transitorio}

"Mientras la ley no disponga otra cosa, las concesiones mineras para explorar y explotar, se someterán a la tramitación establecida en el actual Código de Minería. Las concesiones exclusivas para explorar y las manifestaciones inscritas, que se encuentren vigentes, no darán otra facultad que la de obtener dichas concesiones para explotar".

Redactada de esta forma la garantía constitucional al derecho de dominio, no existe sombra de duda de que el Proyecto de Reforma Agraria puede aplicarse en su integridad y que ninguna de sus disposiciones quedará fuera de la órbita que señala la Carta Fundamental.

El Proyecto Especial de Reformas a la Constitución Política del Estado ha alcanzado ya su segundo trámite constitucional y, a no dudarlo, será ley de la República antes que el Proyecto de Reforma Agraria, con lo cual desaparecen todas las inquietudes jurídicas sobre la constitución de esta última iniciativa.

\section{III. - LEGISLACION DE EMERGENCIA EN MATERIA DE DIVISION DE PREDIOS AGRICOLAS, LEY 16.465. DE 23 DE ABRIL DE 1966.}

\section{Sumario del punto:}

1.-Fundamento del Proyecto.

2.- Requisitos para dividir predios de una cabida superior a 80 hectóreas.

3.-Definiciones.

4.- Excepciones.

5.-La Cora califica a los adquirentes.

6.- Indemnización.

7.-Asistencia técnica y crediticia.

8.- Indivisibilidad.

9.-Sanciones.

\section{1.-Fundamento del Proyecto.}

Durante la discusión parlamentaria del Proyecto de Ley de Reforma Agraria, que ya alcanza a 6 meses, y como un acto preparatorio a su promulgación, el Ejecutivo, a petición de las organizaciones sindicales campesinas, envió al Congreso un Proyecto que impide parcelar los fun- 
dos de una cabida superior a 80 hectáreas, sin previa outorización de la Corporación de la Reforma Agraria.

Los fundamentos del Proyecto fueron expuestos en el Mensaje. Allí se dice:

"Con fecha 23 de noviembre de 1965 se envió a la H. Cámara de Diputados el proyecto de ley de reforma agraria, que es uno de los más importantes que mi Gobierno ha sometido a la consideración del $\mathrm{H}$. Congreso.

Sin embargo, como se trata de una materia que requerirá detenido esturio, su tramitación demorará algún tiempo.

Dicho proyecto tiende a modificar el régimen de tenencia de la tierra, fundamentalmente por medio de la expropiación de predios rústicos para entregarlos postericrmente en propiedad a los campesinos.

Muchos propietarios, ante la idea de legislar sobre la materia han procedido a dividir, parcelar o hijuelar sus predios, sin sujetarse a normas técnicas, lo que ha acarreado grave daño a la productividad de los mismos, y lo que es más grave, sin considerar la situación de los actuales trabajadores de la tierra, por lo que se hace necesario legislar sobre el particular, a fin de que el Estado vele para que dichas divisiones se hagan en forma adecuada, tanto desde el punto de vista técnico como social.

Con este objeto, mediante el presente proyecto de ley se propone que la Corporación de la Reforma Agraria sea el organismo encargado de autorizar toda división, parcelación o hijulación de un predio rústico de superficie superior a 80 hectárears. Dichas autorizaciones sólo se podrán otorgar si un porcentaje de predio se transfiera a los campesinos, arrendatarios y medieros del predio rústico que se trate de dividir, parcelar o hijuelar. Entiéndese por predio rústico todo predio agrícola o ganadero, esté comprendido en zonas rurales o urbanos".

Convertido este Proyecto en Ley de la República, sus principales disposiciones son las siguientes:

2.-Requisitos para dividir predios de una cabida superior a 80 hectóreas.

"Artículo 1․- Prohíbese la división. parcelación o hijuelación de todo predio rústico de superficie superior a 80 hectóreas, sin previa cutorización del Consejo de la Corporación de la Reforma Agraria.

Dicha cutorización no podró otorgarse sino cuando se cumplan los siguientes requisitos:

a) Que las hijuelas o parcelars proyectadas constituyan unidades económicas de producción:

b) Que la división se efectúe de acuerdo con normas técnicas que garanticen el buen aprovechamiento de los recursos naturales existentes en el predio, $Y$

c) Que el propietario se obligue a transferir en dominio a los jefes de familias campesinas que hayan trabajado en forma permanente en el predio por lo menos tres de los últimos cuatro años anteriores a la fecha de la solicitud de autorización, a lo menos el $40 \%$ de la superficie total del predio que se trata de dividir, considerando las diferentes clases de suelo, así como las aguas necesarias para su racional aprovechamiento". 
3.-Definiciones.

"Para las efectos de esta ley, entiéndese que la parcela o hijuela es una unidad económica de producción no sólo en el caso de que cumpla por sí sola las exigencias técnicas correspondientes, sino, además, cuando la división del predio reserve para el goce común extensiones de terrenos complementarios que habiliten al dueño de la hijuela o parcela para el aprovechamiento cabal de los recursos naturales existentes en ella.

Para los efectos de esta ley se entenderá por farmilia campesina aquella en que uno o más de sus miembros laboren la tierra, ya sea en calidad de empleado u obrero agrícola, mediero o arrendatario de una superficie no superior a la de la unidad económica definida en la letra b) del artículo $11^{\circ}$ de la Ley $N^{\circ}$ 15.020. En ningún caso podrán adquirir dentro del porcentaje que el propietario está obligado a transferir a los jefes de familias campesinas, aquellos que sean dueños de una superficie de tierra igual o superior a la de la referida unidad económica".

\section{4.- Excepciones.}

"En el caso que el predio rústico que se trate de dividir, parcelar o hijuelar, perteneciere $\alpha$ dos 0 más personas on común, que lo hayan adquirido por sucesión por carusa de muerte 0 la disolución de una sociedad conyugal, podrá el Consejo de la Corporación de la Reforma Agraria fijar el porcentaje de los terrenos que deberán ser transferidos a los campesinos, medieros o arrendatarios, pudiendo, incluso, en casos calificados, eximir a los propietarios de esta obligación.
Entiéndese por predio rústico todo predio agrícola o ganadero, ya sea que estó comprendido en zonas rurales o urbanas; asimismo, se entenderá que forman un solo predia los terrenos contiguos que pertenecen a un mismo dueño.

No estarán afectos a las disposiciones del presente artículo las divisiones, hijuelariones o parcelaciones de predios forestales o de aptitud exclusivamente forestal. Estas calidades se acreditarán mediante certificado otorgado por la Dirección de Agricultura y Pesca, el que deberá insertarsé en la escritura correspondiente".

\section{5.- La Cora califica a los adquiren- tes.}

"Artículo 2\%- Corresponderá a la Corporación de la Reforma Agraria calificar a los jefes de las familias campesinas adquirentes de la tierra, así como aprobar las condiciones del contrato que para la transferencia de las respectivas parcelas celebren con los propietarios. El plazo para pagar el saldo del precio, si lo hubiere, se determinará sobre la base de a capacidad de pago de los campesinos, no pudiendo exceder de 15 años, a menos que las partes acuerden un plazo mayor.

En caso de no existir en el predio que se trate de dividir, hijuelar o parcelar jefes de familias campesinas suficientes para adquirir las parcelas que se formen, dentro del porcentaje de tierras que el propietario está obligado a trasferirles, se dará preferencia para adquirir el resto de ellas a los jefes de familias campesinas del predio que haryan trabajado en él menos de tres años. En caso que aún quedaran parcelas sobrantes, se deberán enajenar a otros jefes de fami- 
lias campesinas, oún cuando no laboren en el predio que se trate".

\section{6.-Indemnizaciones.}

"En caso de dividirse un predio rústico con autorización del Consejo de la Corporación de la Reforma Agraria, el propietario deberá pagar a los empleados $\mathrm{y}$ obreros agrícolas del predio, siempre que no adquieran ninguna de las parcelas o hijuelas, 0 que no tuvieren derecho a ellas, una indemnización equivalente a dos años de sus remuneraciones".

\section{7.- Asistencia técnica y crediticia.}

"Artículo 3". - La Corporación de la Reforma Agraria $\mathrm{y}$ el Instituto de Desarrollo Agropecuario deberán prestar asistencia técnica y crediticia en forma preferente a las familias campesinas adquirentes de este tipo de parcelas, con el fin de asegurarles el buen resultado de la explotación de sus predios, siempre que estén constituidos en cooperativas o en comités de pequeños propietarios.

La Corporación de la Reforma Agraria o el Instituto de Desarrollo Agropecuario podrán también proporcionar ayuda crediticia a las familias campesinas para pagar el todo o parte del precio de adquisición de las tierras que se le transfieran en conformidad a las disposiciones de la presente ley, o garantizar su pago".

\section{8.- Indivisibilidad.}

"Las parcelas adquiridas por familias campesinas no podrán dividirse, ni sus titulares enajenarlas dentro del plazo de 15 años, contado desde la inscripción del respectivo título de dominio, sin previa autorización de la
Corporación de la Reforma Agraria. Dicha Institución sólo podrá autorizar su enajenación a otro jefe de familia campesina".

\section{9.- Sanciones.}

La ley No 16.465 es, por otra parte, bastante drástica en materia de sanciones, por cuanto castiga todo acto ejecutado o contrato celebrado, en contravención a las normas antertormente transcritas, con la nulidad de los mismos, estableciendo, además, una sanción pecuniaria que deberá cancelar el propietario del predio dividido. Esta multa, en beneficio de la Corporación de la Reforma Agraria, equivaldrá al $20 \%$ del avalúo total que el predio tiene para los efectos de la contribución territorial vigente a la fecha del acto o contrato en que consta la división.

Estos antecedentes nos parecen ya adecuados para iniciar el estudio propiamente tal del Proyecto de Reforma Agraria. En efecto, conocemos ya los fines del Proyecto, las metas que se persiguen, la necesidad que ha habido de acelerar la enmienda del artículo 10 № 10, de la Carta Fundamental, para hacer posible la aplicación de los preceptos del Proyecto de Reforma Agraria, y, finalmente, la legislación de emergencia que se ha dictado - Ley 16.465- para evitar las parcelaciones brujas tendientes a alterar el status de las tierras existente a la fecha del comienzo del estudio del Proyecto de Reforma.

Veamos ahora los caminos o procedimientos ideados por el legislador para efectuar una redistribución masiva de los derechos de dominio sobre tierras rústicas. Estos caminos no son otros que las Causales de Expropiación. 


\section{CAPITULO II.}

\section{DE LAS CAUSALES DE EXPROPIACTON}

\author{
I.- Primera causal: \\ II.- Segunda causal: \\ III.- Tercera causal: \\ IV.- Cuartá causal: \\ V.- Quinta causal: \\ VI.- Sexta causal: \\ VII.- Séptima causal:
}

VIII.- Octorva causal:

IX.- Novena causal:

X.- Décima cousal:

\section{¿Cuáles son los predios que se expropiarón?}

El artículo $2^{\circ}$ del Proyecto expresa que, con el objeto de que la propiedad cumpla su función social, se declaran de utilidad pública y se autoriza la expropiación, total o parcial, de los predios rústicos que se encuentrom en cualquiera de las 10 si: tuaciones que veremos más adelante. Resulta útil recordar que el artículo lo define, a su vez, qué debe entenderse por predio rústico, diciendo que es tal, todo predio agrícola, ganadero o forestal, ubicado en zonas rurales o
Exceso de superficie.

Abandono o mala explotación.

División de predios con posterioridad al 4 de Noviembre de 1964.

Predios rústicos pertenecientes a personas jurídicas.

Infracción por los propietarios, a las normas sobre arrendamientos agrícolas.

Predios rústicos pertenecientes a comunidades.

Predios rústicos ubicados en la zona de aplicación de la ley de propiedad custral.

Predios rústicos que se encuentren comprendidos dentro de un área de riego.

Predios rústicos que constituyan minifundios.

Predios que sea necesario adquirir para completar un programa de Reforma Agraria.

urbanas. De tal manera que, prácticamente, queda autorizada la expropiación de cualquier casco de tierra que tenga alguna aptitud de aprovechamiento agrícola, ganadero o forestal.

No obstante lo anterior, es de pública notoriedad que el Proyecto no pretende, ni con mucho, la expropiación de todas las tierras de Chile.

"Lo único que quisiera afirmar es que de 260 mil propiedades agrícolas hay seguramente 256 mil propiedades agrícolas que, por tener superficie en diversas regiones del país, no serán prácticamente afectadas por esta re-

1) Mensaje Presidencial del 21 de Mayo de 1966, página 25. 
forma. Sólo serán afectadas alrededor de 4.000 propiedades que hoy representan aproximadamente la mitad de la superficie agrícola del país".(1).

"Este cambio estructural profundo, a pesar de todo lo que insistentemente se ha venido repitiendo en forma intencionada por parte de algunas minorías, no atenta contra el empresario eficiente. Por el contrario se puede asegurar que consolidará su posición. El Proyecto establece la expropiación sobre el excedente de 80 hectáreas de riego básicas o su equivalente en las demás regiones del país. En el caso de propietarios que cumplan con determinados niveles de eficiencia $y$ sean respetuosos cumplidores de la legislación social vigente, este máximo es cuatro veces superior. Esto quiere decir que pueden conservar en su poder hasta 320 hectáreas de riego básicas o su equivalente.

Nadie en el país podró discutir que 80 hectáreas de riego en el Valle del Maipo ó 320 hectáreas, según sea el caso, 600 hectóreas en el Llano Central de Valdivia ó 2.400 hectóreas; 500 hectáreas en el Llano Central de Osorno ó 2.000 hectáreas, según las circunstancias, pueden considerarse superficies de tomaño inadecuado para realizar explataciones técnicamente aconsejables $\mathrm{y}$ obtener importantes ingresos. Aún más, el conocimiento del país y de la experiencia de buenos productores que vean reducida su área verón aumentados sus ingresos." (2).
I.- PRIMERA CAUSAL: EXCESO DE SUPERFICIE.

\section{Sumario del Punto:}

1.- Principio General.

2.- Concepto de las 80 hectáreas de riego básicas. Tabla de Equivalencias.

3.- Situación de las comunidades y del derecho que les asiste para adquirir tierras en relación con los predios expropiados.

4.- Situación de la sociedad conyugal.

5.- Superficie de tierra que puede reservarse un propietario en forma ordinaria: 80 hectóreas.

6.-Derecho de reserva especial o primera excepción a la expropiabilidad.

7.- Plazo para hacer valer los derechos de reserva.

8. - Ubicación de los terrenos de la reserva.

9.-- De las reclamaciones sobre el acuerdo recaído en materia del derecho de reserva que corresponde a los propietarios.

10.- De la caducidad del derecho de reserva especial.

11. - Los derechos de aprovechamiento de aguas en relación con los terrenos que quedan en poder de los propietarios agrícolas.

\section{1.- Principio General.}

Son expropiables los predios rústicos de que sea dueña una misma persona natural, cualesquiera que sea su ubicación en el territorio nacional y las categorías de sus terrenos que, cisladamente 0 en conjunto, tengan

2) Mensaje Presidencial citado, página 235. 
una extensión que exceda de 80 hectóreas de riego básicas, calculadas conforme a la Tabla de Conversión que se establece en el artículo 157 del Proyecto.

Esta primera cousal de expropiación plantea varias cuestiones que debemos analizar en la forma más sistemática posible.

\section{Concepto de las 80 hectáreas de riego bósicas. Tabla de Equivalen- cias.}

Con el fin de que la propiedad no continúe concentrada en unas pocas manos y para que los campesinos, arrendatarios $y$ ocupantes tengan acceso al dominio de la tierra que trabajan, el proyecto declara expropiables los predios pertenecientes a personas naturales, que excedan de 80 hectáreas de riego básicas. El Proyecto de la reforma ha fijado un límite, sociamlente aceptable, pasado el cual operan las expropiaciones de los predios rústicos. Sin embargo, sería un grove error considerar que este límite es fijo para todo el país, pues una tabla de equivalencias ha considercdo las diferentes calidades del suelo; terrenos arables de riego, do secano, terrenos no arables, cerros, etc; la ubicación de los terrenos por provincia, incluso en algunos casos por comunas y dentro de ellas por zonas, de cordillera y valles interiores especiales, etc.

No obstante las consideraciones precedentes, creemos que no existe nada más gráfico para apreciar el concepto de 80 hectáreas de riego básicas, que examinar una parte de la Tabla de Conversión, a que alude el artículo 157 del Proyecto, haciéndose presente que la Tabla comienza en el Valle del Lluta (Arica) y termina en la Isla Navarino (Magallanes). La visión parcial que ofrecemos a continuarión sólo comprende a las equivalencias de 80 hectóreas de riego básicas en las provincias de O'Higgins, Colchagua y Curicó, no obstante lo cual resulta relativamente fácil saber si un fundo, dentro de dicha zona, está o no afectado por ia causal de exceso de cabida. Para ello es necesario saber si el fundo se encuentra en la cordillera, llano central o terrenos de la costa. Determinado este punto, habrá que saber si el fundo es arable o no arable. Todavía, si es arable, deberemos averiguar si el predio es de riego o de secano. Con estos datos, deberemos, por último, confrontar la superficie del predio rústico que se nos consulta con la cabida máxima admisible según la provincia y así sabremos si el fundo es o no expropiable por exceso de cabida. (*).

Así las cosas, tomando en cuenta el régimen de reserva que el Proyecto consagra, el agricultor que trabaje directamente sus tierras, a través de una explotación medianamente satisfactoria, tiene casi la certidumbre de que podró conservar en su dominio 80 hectóreas de riego básicars o su equivalencia en la Tabla de Conversión.

No olvidemos, por otra parte que, cuando la suma de las superficies de los predias de que sea dueña una misma persona natural, exceda de 80 hectáreas de riego básicas, será expropiable cualquiera de esos predios, o parte de alguno de ellos, o la totalidad de éstos, sin perjuicio del derecho de reserva que corresponda en conformidad a las preceptos que más adelante estudiaremos.

(*) Ver cuadro en página XX del frente. 


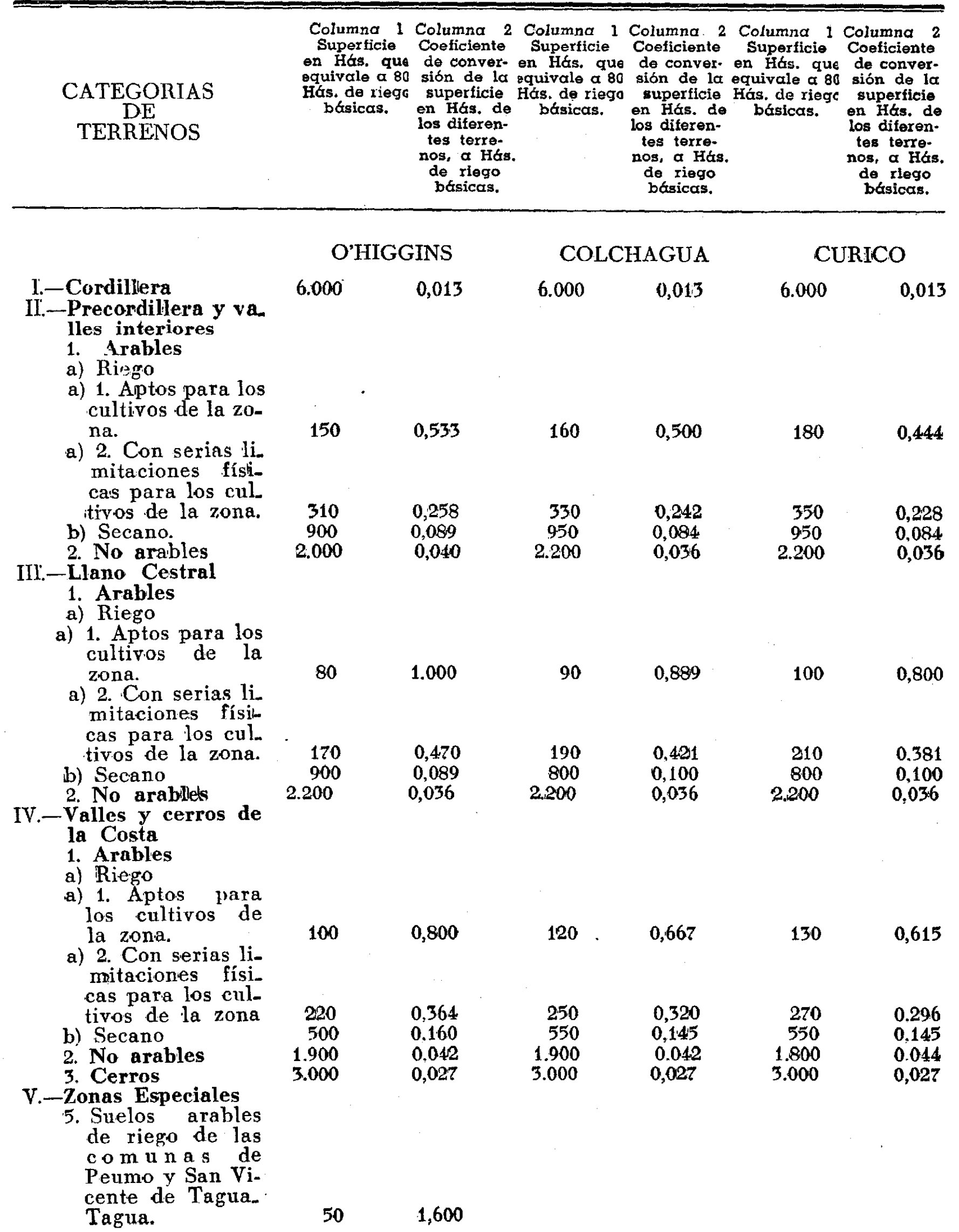


3.- Situación de las comunidades y del derecho que les asiste para adquirir tierras en relación con los predios expropiados.

Sin perjuicio de que al analizar la sexta causal de expropiación, que afecta a los predios rústicos pertenecientes a las comunidades, hagamos algunas consideraciones sobre el tema, debemos ahora destacar que son expropiables los predios pertenecientes $\alpha$ una comunidad, cuancio la superficie de los predios rústicos de que ella sea propietaria sea superior al límite de 80 hectáreas, a menos que se trate de las comunidades agrícolas de las Provincias de Coquimbo y Atacama, que se rigen por el D. F. L. R. R. A. No 19, de 1963, ni a las tierras comunes indígenas regidas por la Ley 14.511, ni a las comunidades tradicionales que determine el Presidente de la República por decreto supremc dictado en el plazo de 180 días contados desde la vigencia de la ley.

En el caso de expropiarse por exceso de cabida, tierras de que sean dueñas 2 ó más personas en común, cada uno de los comuneros que estuvieren explotando personal o efectivamente las tierras tendrán derecho a adquirir, en el predio expropiado, una superficie de terrenos, expresada en hectáreas de riego básicas, equivalente a la que estuviere explotando de alguno de esos modos.

La superficie que los comuneros titulares de este derecho adquieran no podrá exceder, en conjunto, de 80 hectóreas de riego básicas ni podrá ser superior, para cada uno de ellos, a esa misma superficie, computada la de otros terrenos que tuvieren en su dominio expresada en hectáreas de riego básicas.

No obstante, en el caso de que los comuneros que tuvieren este derecho fueren dos o más, el límite máximo de terrenos que pueden adquirir en conjunto, se ampliará en 10 hectáreas de riego básicas por cada uno de ellos.

Muy importante. No podrá hacer valer el derecho de adquisición el comunero que tuviere los terrenos abandonados o mal explotados.

El plazo para hacer valer el derecho de adquisición de tierras $\mathrm{y}$ de que son titulares las comunidades a las que se les expropie sus predios por exceder estos el máximo permitido, la ubicación de esas tierras y las reclamaciones respectivas, se tramitarán en la misma forma que veremos en los números 6,7 У 8 .

\section{4.- Situación de la Sociedad con- yugal.}

Los predios pertenecientes a personas casadas se consideran como un solo todo para los efectos de la expropiación, aún cuando estén se parados de bienes, excepto el caso de que estén divorciados a perpetuidad. Por tanto, si una sociedad conyugal tiene en su haber predios rústicos de que sean, dueños uno u otro cónyuge, o ambos en común, $\mathrm{y}$ estos predias excedan de 80 hectóreas de riego básicas, será expropiable cualquiera de esos predios, o parte de algunos de ellos, o la totalidad de éstos, $\sin$ periuicio del derecho de reserva que veremos a continuación.

\section{5.- Superficie de tierra que puede re- servarse un propietario en forma ordinaria: 80 hectáreas.}

Acordada la expropiación del todo o parte de un predio rústico, o de varios predios pertenecientes a una mis- 
ma persona natural, por exceso de cabida, ¿puede el propietario conservar una parte de su predio?

En conformidad con el artículo 12 del Proyecto, el propietario afectado por esta caruscl de expropiación tiene derecho a conservar en su dominio una superficie de terreno que no exceda de 80 hectóreas de riego báricas, computada la de otros terrenos de que fuere dueño, expresada en hectáreas de riego básicas.

Si el propietario tuviere más de 5 hijos que trabajen con él o vivan a sus expensas, el límite máximo de superficie mencionado se aumentará en 10 hectáreas de riego básicas por cada una de esos hijos que excedieren de 5, sin que el total de la reserva pueda ser superior a 100 hectóreas de riego básicas.

El propietario sólo puede ejercer el derecho de reserva a que se refierere este apartado, cuando los terrenos no están arrendados o cedidos para su explotación por terceros $Y$ esto hay que tenerlo muy presente; jamás el propietario tendrá el derecho de reserva cuando su predio estuviere abandonado o mal explotado.

Para los efectos de la reserva, en el caso de las personas casadas, se considerarán como un todo los predios de que sean dueños ambos cónyuges caún cuando estén separados de bienes, excepto el caso de que estén divorciados a perpetuidad.

\section{6.-Derecho de reserva especial o primera excepción a la expropia- bilidad.}

A.- Requisitos que debe reunir el propietario para obtener la inexpropiabilidad de 320 hectáreas de riego bórsicas. a) Tener dedicada a cultivos anuales, cultivos permanentes o praderas artificiales, a lo menos el $95 \%$ de la superficie útil de riego normal del predio de que se trate; en el caso de terrenos de secano, éstos deberán estar dedicados a cultivos anuales o permanentes o $a$ praderas naturales mejoradas 0 artificiales, a lo menos el $80 \%$ del total de la superficie apta para ello.

b) Explotar el predio en condiciones técnicas superiores al promedio de los predios de la comuna.

c) Mantener en buen estado de conservación el suelo $\mathrm{y}$ otros recursos naturales renovables.

d) Conceder a los trabajadores del predio participación en las utilidades de la explotación, en los términos establecidos en la legislación sobre participaciones.

e) Pagar por concepto de salarios, sueldos y participaciones a que se refiere la letra anterior, a los obreros $\mathrm{y}$ empleados del predio, un total anual de por lo menos dos veces el salario mínimo campesino Y sueldo vital de escala B. del Departamento respectivo en relación con el número de jornadas y meses trabajados. Para estos efectos, sólo se computará el valor de las regalías en to que no excedan del $25 \%$ del monto total de los sueldos $y$ salarios pagados. En salarios $y$ participaciones pagados $a$ los obreros se calcularán separadamente de los sueldos y participaciones pagados a los empleados u obreros.

f) Cumplir con todas las disposiciones en la que respecta a vivienda campesina, educación $y$ sanidad y no haber sido condenado por 
sentencia judicial o resolución administrativa ejecutoriada por infracción a la legislación social y del trabajo, ocurrida en los 2 años anteriores al acuerdo de expropiación.

g) Si el propietario fuere una persona natural deberá, además, estar explotando los terrenos directormente, $y$, si fuere persona jurídica, sólo podrán ejercer este derecho aquellas cuyas actividades tengan por objeto principal la explotación agrícola o ganadera y siempre que los predios de que se trata no estén dados en arrendamiento o mediería o concedidos de cualquier otra forma para su explotación por terceros.

Para los efectos de este artículo, en el caso de las personas casadas, se considerarón como un todo los predios de que sean dueños ambos cónyuges aún cuando estén separados de bienes, excepto el caso de que estén divorciados a perpetuidad.

\section{B.- Superficie máxima cuya reserva puede obtener el propietario: 320 hectóreas.}

La superficie de terrenos excluidos de la expropiación en virtud de este crtículo, no podrá exceder de 320 hectáreas de riego básicas, incluida en ella la de los terrenos que el propietario puede reservarse en virtud del derecho de reserva que analizamos en el $N^{\circ} 5$ anterior (80 hectáreas de riego básicas, 90 hectáreas si el propietario tuviere 6 hijos, 100 hectáreas, si el propietario tuviere 7 o más hijos que trabajen con él o vivan a sus expensas) y computada la superficie de otros predios de que fuere dueño, expresada en hectáreas de riego básicas.
El móximo de 320 hectáreas excluidas de la expropiación quedarán inexpropiables en el futuro, aunque esta superficie exceda del límite que se considera socialmente aceptable, (80 hectáreas de riego básicas) pero, naturalmente pueden ser expropiadas en cualquier momento, si los propietarios dejaren de cumplir alguno de los requisitos o condiciones que les permitieron obtener la inexpropiabilidad.

\section{7.-Plazo para hacer valer los dere- chos de reserva.}

\section{a) Derecho de reserva ordinario.}

Ell propietario que desee hacer uso del derecho de reserva ordinario $(80$ hós. de riego básicas), deberá declararlo por escrito ante la Corporación de la Reforma Agraria, dentro del plazo de 30 días contado desde la fecha de la notificación del acuerdo de expropiación.

\section{Si así no to hi ciere, se extinguirá definitivamente ese derecho.}

b) Derecho de reserva especial.

El propietario que desee hacer uso del derecho de reserva especial, (hasta 320 hás. de riego básicas) deberá hacer valer este derecho ante la Corporación de la Reforma Agraria, dentro del plazo de 30 días contado desde la notificación del acuerdo de expropiación, debiendo acompañar a su solicitud los documentos que el reglamento exija bajo apercibimiento de no admitir su solicitud a tramitación. Corresponderá al Consejo de la Corporación pronunciarse sobre la solicitud, para la aprobación de la cual se requerirá el voto favorable de los $2 / 3$ de sus miembros presentes, a lo menos.

Si la solicitud del propietario fuere denegada, éste podrá recurrir al Consejo Nacional Agrario, dentro del pla- 
zo de 30 días, contados desde la fecha en que se le notifique el respectivo acuerdo de la Corporación.

El derecho especial de reserva es intransferible.

\section{8.- Ubicación de los terrenos de la reserva.}

La ubicación de los terrenos objeto de la reserva a que se refleren los artículos $12^{\circ}$ (80 hás.) y $15^{\circ}$ (hasta 320 hás.), se determinará con arreglo a las siguientes normas:

a) Los terrenos que al propietario corresponda conservar en su dominio, deberón constituir en lo posible una superficie continua y si la forma del predio lo permite, conexa;

b) Se deberón distribuir proporcionalmente entre los terrenos que el propietario conserve en su dominio $\mathrm{y}$ caquellos que constituyan la parte expropiada, tierras de calidad y condiciones semejantes;

c) La parte de los terrenos que el propietario conserve en su dominio con frente a camino público, deberá ser, en lo posible, proporcional a la superfiie del predio;

d) Los terrenos que el propietario conserve en su dominio deberán ubicarse de manera que no impidan el racional aprovechamiento de las aguas en los terrenos expropiados;

e) Deberá incluirse en los terrenos que el propietario deba conservar en su dominio, la casa patronal, siempre que así lo solicite; $Y$

f) Que la distribución de las mejoras entre la parte de los terrenos que el propietario conserve en su dominio y la parte que resulte efectivamente expropiada se haga de manera que no perjudique su racional aprovecha miento.
No obstante lo anterior, el propietario y la Corporación de la Reforma Agraria podrán acordar una ubicacación diferente a los terrenos que el primero deba conservar en su dominio.

En el caso que no hubiere acuerdo, el propietario deberá manifestar por escrito, y dentro del plazo de 15 días contados desde la fecha en que la Corporación le notifique el desacuerdo, la ubicación de los terrenos que desee conservar en su dominio, ateniéndose a loss normas señaladas en las letras a) a f) precedentes. No tendrá este derecho el propietario que tenga arrendado parcialmente el predio expropiado, correspondiendo la determinación definitiva a la Corporación.

Si el propietario no determina la ubicación dentro del plazo mencionado en el pórrafo anterior, la Corporación la señalará definitivamente.

En caso que el propietario señalare la ubicación de los terrenos que desee conservar en su dominio, pero no se ajustare a las normas establecidars en las letras a) a f), la Corporación de la Reforma Agraria podrá solicitar al Tribunal Agrario Provincial, dentro del plazo de treinta días contados desde la fecha en que el propietario haya manifestado por escrito la ubicación de los terrenos, que la determine en definitiva.

El Tribunal Agrario Provincial conocerá de la reclamación conforme $a$ las reglas de los incidentes y fallaráá en única instancia.

El Tribunal deberá fallar la reclamación de la Corporación dentro del plazo de treinta días, contado desde la notificarción del reclamo del propietario. 
9.-De las reclamaciones sobre el acuerdo raccádo en materia del derecho de reserva que corresponde $\alpha$ los propietarios.

Si se expropiare un predio por la causal establecida en el artículo $3^{\circ} \mathrm{y}$ no se reconociera al propietario el derecho de reserva que le correspondiere, podrá éste reclamar, ante el Tribunal Agrario Provincial, dentro del plazo de quince días contados desde la notificación del acuerdo del Consejo Nacional Agrario.

No obstante, en este último caso, si a petición de la Corporación, el Tribunal estimare que con la restitución de los terrenos de la reserva al propietario se causaría un grave perjuicio a los intereses de la comunidad, por estar ejecutando trabajos de parcelación u otras obras en ellos o por cualquiera otra circunstancia calificada, ordenará se le pague en cambio el valor de la reserva calculado de conformidad con el artículo 45 , con un $20 \%$ al contado y el saldo en bonos de la Reforma Agraria de la clase " $\mathrm{B}$ ", cuya amortización es de 5 años.

\section{0.- De la caducidad del derecho de reserva especial.}

La inexpropiabilidad declarada a propósito del derecho de reserva especiarl, harsta 320 hectáreas de riego básicas, caducará en el caso de que los propietarios dejaren de cumplir, en cualquier momento, alguno de los requisitos o condiciones que les permitieron obtener la inexpropiabilidad.

Ia caducidad será declarada, en primera instancia, por el Tribunal Agrario Provincial, a petición de la Corporación de la Reforma Agraria o del Ministerio de Agricultura.
11.- Los derechos de aprovechamiento de aguas en relación con los terrenos que quedan en poder de los propietarios agrícolas.

Cuando un propietario conserve terrenos en su dominio, ya sea por expropiarse parcialmente un predio 0 a consecuencia de la aplicación de los derechos de reserva ordinario o especial, la Dirección de Aguas concederá el derecho de aprovechamiento conforme a los preceptos del proyecto de ley de Reforma Agraria, en relación con el número de hectáreas de riego que tengan esos terrenas.

\section{II.- SEGUNDA CAUSAL. ABANDO- NO O MALA EXPLOTACION.}

\section{Principio General.}

Conforme al artículo $4^{\circ}$ del Proyecto, son expropiables los predios rústicos que se encuentren abandonados - los que estén mal explotados.

\section{Cuándo se aplica la causal.}

a) Respecto de aquellos predios rústicos que desde una fecha anterior al 27 de Noviembre de 1962, tenían una superficie no superior a las 80 hectóreas de rlego básicas, esta causal de expropiación por abandono o mala explatación sólo se aplicará una vez que trascurran 2 años, desde que se publique la nueva ley de Reforma Agraria. La fecha del año 1962 corresponde a la de promulgación de la ley 15.020, primer ensaryo de $\mathrm{R}_{\theta-}$ forma Agraria.

b) Respecto de los demás predios rústicos, esta causal de expropiación podrá aplicarse de inmediato.

Debemos dejar expresamente consignado que los conceptos de predio 
abandonado $\mathrm{y}$ de predio mal explotado, han sido definidos en el artículo 19 del Proyecto, en la siguiente forma:

Definición de predio abandonado: Aquél que no es objeto de hechos positivos de explotación económica como cultivos agrícolas, empastadas, crianza de ganado, cuidado y conservación de los bosques naturales o artificiales, u otros de análoga signifiEación económica. El hecho de que el predio esté cercado o que tenga cuidadores o la existencia de construcciones o la simple explotación de subsistencia, no constituirá por sí sólo prueba de explotación económica.

Definición de predio mal explotado: Aquél cuya productividad se encuentra por debajo de los niveles adecuados en relación a las condiciones ecorómicas predominantes en la región para tierras de análogas posibilidades.

Siempre se reputará mal explotado el predio cuya superficie sea superior a quince hectáreas de riego básicas, que no reuna en forma conjunta las siguientes condiciones.

1) Tener a lo menos el $80 \%$ de su superficie útil de riego normal ocupada con cultiovs anuales, cultivos permanentes $o$ praderas artificiales; en el caso de terrenos de secano, éstos deberán estar dedicados a cultivos anuales, a lo menos en el $70 \%$ del total de su superficie con aptitud para estos fines.

2) Tener abonado por lo menos el $50 \%$ de la superficie cultivada total con dosis de fertilizantes consideradas normales para los tipos de cultivos $Y$ zonas de que se trate. Estas dosis serán las que determinen las instrucciones técnicas del Ministerio de Agricultura.
3) Tener inversiones en capital fijo y realizable cuyo valor equivalga como mínimo al valor de tasación fiscal del casco del predio.

4) Cumplir con todas las disposiciones legales en lo que respecta a vivienda compesina, educación Y sanidad y no haber sido condenado por sentencia judicial o resolución administrativa ejecutoriada por infracción a la legislación social y del trabajo, ocurrida en los dos años anteriores al acuerdo de expropiación.

El peso de la prueba de los diferentes requisitos a que se refiera esta letra corresponderá al propietario.

\section{III.- TERCERA CAUSAL: DIVISION DE PREDIOS RUSTICOS CON POSTERIORIDAD AI 4 DE NO- VIEMBRE DE 1964 (Artículo 5\%).}

Sumario del punto:

1.- Principio General.

2.-Definiciones.

3.- Fundamento de la causal.

4.- Artículo Transitorio

\section{1.-Principio General.}

El artículo 5 del Proyecto declara expropiable los predios rústicos que hubieren resultado de la división de un predio de superficie superior a 80 hectáreas de riego básicas, cuando la división se haya efectuado con posterioridad al 4 de Noviembre de 1964. fecha en que se inició el Goblerno, siempre que a la iniciación del año agrícola inmediatamente siguiente a la fecha de la división no se haya hecho materialmente efectiva la división de la explotación y los predios resultantes de la subdivisión no hayoun sido objeto de explotación per- 
sonal o. efectiva, independiente $\mathrm{y} d e$ modo ininterrumpido.

Todos los predios que no cumplan los requisitos anteriores serán exproptables, cualesquiera sean sus propietarios y su superficie.

La prueba de que el predio ha sido explotado personal o efectivamente $y$ en forma independiente de modo ininterrumpido desde la iniciación del año agrícola inmediatamente posterior a la fecha de la división corresponderá siempre al propietario.

Esta causal de expropiación sólo será aplicable por el plazo de tres años a contar desde la fecha de vigencia de la ley de Reforma Agraria respecto de los predios que se hayan dividido con anterioridad a ella.

\section{2.-Definiciones.}

Debe recordarse que el artículo $1^{\circ}$ de la ley ha definido los conceptos de explotación directa, explotación efectiva y explotación personal, en la forma que se transcribe a continuación:

Explotación Directa: La realizada por una persona natural que explota tierras por su cuenta y riesgo, dirige por si misma la explotación y participa en ella. En casos calificados, como el de ser el propietario de avanzada edad 0 encontrarse imposibilitado físicamente para el trabajo, se estimará que existe explotación directa cuando la dirección y participación de la explotación la efectúe un Administrador cuya actividad básica sea la administración de la tierra del propietario.

Explotación Efectiva: La explotación efectuada por una persona natural que, además, trabaja de modo habitual en las tierras, constituyendo este trabajo su actividad básica.
Explotación Personal: La explotación directa realizada por una persona natural que trabaja de modo continuo en las tierras, constituyendo este trabajo en actividad básica y que realiza dicha explotación con el solo aporte de su trabajo personal y el de los miembros de su familia que con él conviven, empleando asalariados sólo con carácter ocasional, en número limitado y proporcional a la extención del predio y a la naturaleza de su aprovechamiento.

\section{3.-Fundamento de la causal.}

"El fundamento de la norma que comentamos es el siguiente: para efectuar una reforma agraria que tiene como finalidad dar acceso a la propiedad de la tierra a los campesinos, arrendatarios y ocupantes que la trajaban y, al mismo tiempo, aumentar la producción de manera que el país esté en condiciones de abastecerse de la mayoría de los alimentos, es indispensable contar con tierras. Con este objeto deben expropiarse no sólo aquellas que estén abandonadas, o mal explotadas, sino que también las que excedan de un límite socialmente aceptable, aunque estén bien explotadas.

Ahora bien, cuando se anuncia o se prevé un proceso de reforma agraría la mayoría de los agricultores que tienen conciencia social se esfuerzan por mejorar la producción de sus tierras $\theta$ intensifican la inversión en el campo. Sin embargo, una minoría de ellos no se conforman con la necesidad de la reforma y adoptan medidas de tipo jurídico tendientes a burlar sus efectos. Los hechos descritos se han observado en todos los países en que se ha realizado una efectiva reforma agraria $y$, en consecuencia, el 
legislador ha debido adoptar las medidas correspondientes. Chile no es una excepción al respecto. El mérito de la ley 15.020 fue haber formado conciencia de la imperiosa necesidad de efectuar una reforma agraria. Los buenos agricultores han mejorado la producción de sus campos y muchos de ellos pondrán gozar de la inexpropiabilidad hasta 320 hectáreas de riego básicas. Aquellos que no se conformaron con la posibilidad de una reforma agraria han dividido sus fundos, desde el punto de vista jurídico, con el fin de precaver una expropiación por exceso de superficie, pero han continuado o mantenido la concentración de la explotación. En síntesis han vendido o donado parte de los fundos a hijos, sobrinos u otros parientes, mas continúan explotándolos como una sola unidad.

De la monera descrita se deja sin tierras para hacer la reforma agraria, perjudicándose a los campesinos, medieros, capataces, administradores, técnicos $\mathrm{y}$ arrendatarios $\mathrm{Y}$, también, al no dividirse la explotación se impide el verdadero efecto que la división de la tierra tiene en relación con la producción, causándose un $\mathrm{mal}$ irreparable al país.

En general, en Chile, como es una minoría la que se opone a la reforma agraria, no tiene tanta trascendencia el precepto en estudio. No obstante es necesario, porque como lo demuestran las estadísticas hay algunas zonas en que en las dos últimos años se ha dividido enormemente la tierra sin dividirse la explotación, lo que significa que en esas zonas las posibilidades de los compesinos, medieros, capataces, administradores, técnicos y arrendatarios, serían muy pequeñas, a no mediar la causal de expropiación que analizamos.
De lo expuesto sé infiere claramente que la declaración de utilidad pública de estos predios rústicos no tiene por finalidad sancionar o penar actos jurídicos válidos, puesto que la ley no los declara nulos, sino que persigue recuperar u obtener tierras para realizar la reforma agraria. A nuesto juicio el poyecto es benébolo en esta materia, ya que no exige a los adquirentes de lows unidades divididas que las trabajen directa o personalmente, sino que basta para no incurrir en la causal de expropiación que esas unidades se exploten independientemente.

Por último, es lógico suponer, porque los órganos del Estado actúen de buena fe, que el Consejo Nacional Agrario y la Corporación de la Reforma Agraria aplicarán esta causal de expropiación preferentemente en aquellos casos en que con posterioridad a la vigencia de la nueva ley de reforma agraria se continúen explotando los predios divididos como un solo todo".

\section{Francisco Cumplido}

\section{4.- Artículo Transitorio.}

En relación con esta causal de expropiación, debemos recordar que el artículo li transitorio de la iniciativa en comento, autoriza la expropiación de los predios rústicos de superficie igual o inferior a $\mathbf{8 0}$ hectáreas de riego básicas que hubieren resultado de la división de un predio de superficie superior a la mencionada, cuando la división se hubiere efectuado entre el 21 de Noviembre, de.1965 - fecha del envío del Proyecto de Ley de Reforma Agraria - y la fecha en : que dicho proyecto se convierta en Ley, salvo que la división hubiere sido 
aprobada por el Consejo de la Corporación de la Reforma Agraria.

Lo dispuesto en este artículo transitorio no se aplicará respecto de aquellos predios que se hayan subdividido, durante dicho período, de acuerdo a lo dispuesto en D. F. L. R. R. A. Nং 14. de 1963.

\section{IV.- CUARTA CAUSAL: LOS PRE- DIOS RUSTICOS PERTENECIENTES A PERSONAS JURIDICAS}

\section{Sumario del Punto:}

1.-Principio General.

2.-Excepciones.

3.- Prohibiciones.

\section{1.-Principio General.}

Son expropiables los predios rústicos de que sean dueñas personas jurídicas de derecho público o privado salvo las excepciones establecidas en la presente Ley.

El estudio de esta causal de expropiación incide más bien en las excepciones al principio general.

\section{2.- Excepciones.}

Primera Excepción: En primer término no son expropiables los predios rústicos que pertenezcan a Cooperativas campesinas que cumplan los requisitos que se establecerán en el reglamento que al efecto dicte el Presidente de la República.

Segunda Excepción: Tampoco serón expropiables los predios rústicos de que sean dueñas sociedades de personas que tengan por objeto principal la explotación agrícola o ganadera cuando éstas cumplan con todos $\mathrm{Y}$ cada uno de los siguientes requisitos:

a) Que la superficie de tierra de que la sociedad sea dueña no exceda de 80 hectáreas de riego básicas.

b) Que la dirección de explotación de la totalidad de las tierras de la sociedad sea efectuada por uno de los socios, a lo menos, el que deberá trabajar de modo habitual en esas tierras, constituyendo este trabajo su actividad básica.

c) Que ninguno de los socios lo sea de alguna otra sociedad de personas propietaria de predios rústicos.

d) Que se horyan constituido o declaren su existencia por escritura pública, un extracto de la cual deberá inscribirse en el Registro de Comercio y publicarse en el Diario Oficial en la forma y plazo que establezca el Reglamento.

Tercera Excepción: Los predios rústicos de que sean dueñas sociedades de personas existentes a la fecha de vigencia de la promulgación del Proyecto de Ley de Reforma Agraria, no serán afectados por la causal de expropiación que estamos examinando durante los 180 días siguientes a esa fecha.

Aquellas sociedades de personas existentes a la fecha en que se promulgue el proyecto de ley de Reforma Agraria y que una vez transcurridos los referidos 180 días, reunieren todos los requisitos expresados en las letras b), c) y d), que hemos examinado en la segunda excepción y que sean al mismo tiempo sociedades que tengan por objeto principal la explotación agrícola o ganadera, tendrán derecho a conservar en su dominio una superficie de terrenos que no exceda de 80 hectáreas de riego básicas. 
Si alguno de los socios tuviere más de 5 hijos que trabajen con él o vivan a sus expensas, el límite máximo de superficie se aumentará en 10 hectáreas de riego básicas por cada uno de esos hijos que excediera de ese número, sin que el total de la reserva pueda ser superior a 100 hectóreas de riego básicas.

La sociedad que desee hacer uso del derecho de reserva recién mencionado deberá declararlo por escrito ante la Corporación de la Reforma Agraria dentro del plazo de 30 días contado desde la fecha de la notificación del acuendo de expropiación. Si así no lo hiciere, se extinguirá definitivamente ese derecho.

La ubicación de los terrenos objeto de la reserva se determinará conforme a las reglas que ya examinamos a porpósito del derecho de reserva que corresponde a las personas naturales, motivo por el cual nos remitimos al punto 8 de la primera causal de expropiación.

\section{3.-Prohibiciones.}

A.-Prohibiciones de constituir sociedodes que tengen por objeto explotación agrícola o ganadera.

El artículo 144 del Proyecto prohibe la formación de sociedades anónimas $y$ de sociedades en comandita por acciones que tengan por objeto principal o accesorio la explotación agrícola o ganadera.

Esta prohibición no afecta a las sociedades anónimas que tengan por objeto principal la habilitación de nuevas tierras y su subsecuente explotación en las Provincias de Tarapacá, Antofagasta, Atacama, Coquimbo, Chiloé, Aysén o Magallanes.
Los decretos supremos que autoricen la existencia de sociedardes en las provincias mencionadas se dictarán previo informe del Ministerio de Agricultura.

\section{B.-Prohibición que tienen las socie- dades para adquirir tierras.}

Por exigirlo el interés nacional, el artículo 145 del Proyecto prohibe la adquisición de predios rústicos por parte de las sociedades anónimas o de sociedades en comandita por acciones. Esta prohibición no afecta a las sociedades anónimas existentes $a$ la fecha de vigencia de la Ley, cuyo objeto sea la explotación agrícola o ganadera, como tampoco afecta a las autorizadas para rehabilitar nuevas tierras en los extremos norte y sur del país.

No obstante lo anterior, pueden adquirir predios rústicos, siempre que estén constituidos en su totalidad por terrenos de aptitud exclusivamente forestal, las sociedades anónimas que tengan por objeto la forestación de dichos terrenos y su subsecuente explotación.

\section{V.- QUINTA CAUSAL: INFRACCION POR LOS PROPIETARIOS, A LAS NORMAS SOBRE ARRENDA- MIENTOS AGRICOLAS.}

El artículo $7^{\circ}$ de la iniciativa en estudio, declara expropiables los predios rústicos que se encuentran dados en arrendamiento o cedidos para su explotación por terceros, cuando sus dueños infringieren las disposiciones legales que regulan la materia.

Debe tenerse presente que el artículo 1 . ha definido el concepto de explotación por terceros diciendo: 
Explotación por terceros: La realizada por una persona que no sea el dueño del predio, que dirige por su cuenta y riesgo la explotación, independientemente del propietario. No se considerará explotación por terceros la realizada por el propietario que sea persona natural, conjuntamente con otra u otras personas, siempre que dicho propietario participe tanto en la dirección como en el financiamiento de los gastos de explotación $\mathrm{y}$ en los riesgos de ésta.

Debe considerarse, asimismo, que el artículo 158 del Proyecto, autoriza al Presidente de la República para que, dentro del plazo de 180 días contados desde la fecha de promulgación del ahora proyecto de Reforma Agraria, dicte normas sobre arrendadamiento y otras formas de explotación por terceros y medierías.

Por último, debemos tener presente que hasta que se dicte el nuevo estatuto sobre arrendamientos agrícolas, continuará en vigor DFL. RRA. No 2, de 1963.

Del derecho que asiste a los arrendatarios para adquirir tierras en las tierras que se expropien:

El arrendatario de un predio rústico que se expropie por exceso de cabida, porque el arrendador infrinje las normas sobre arrendamientos agrícolas o por encontrarse el predio comprendido dentro de un área de riego, tiene derecho a que la Corporación de la Reforma Agraria le venda, en esas tierras, una superficie que no podrá ser inferior a la unidad agrícola familiar ni superior a 80 hectáreas de riego básicas.

En ningún caso podrá ejercer el derecho de adquisición, el arrendatario que haya violado las normas que regulen los arrendamientos, o que tenga el predio subarrendado, abandonado o mal explotado o que haya realizado una explotación que hubiere producido el deterioro del suelo.

Tampoco podrá ejercer este derecho la persona que fuere dueña, al tiempo de hacerlo valer, de una superficie de terrenas igual o superior a la unidad agrícola familiar, salvo que enajenare dichos terrenos campesinos, en la forma y condiciones que la Corporación apruebe $\mathrm{y}$ siempre que, $a$ juicio de dicha institución tuviere la apacidad empresarial y económica suficlente. En tal caso dicha persona podrá optar a que la Corporación le enajenare terrenos de hasta 80 hectáreas de riego bósicas en el predio expropiado. En todo caso deberá cumplir las condiciones señaladas en los párrafos anteriores.

\section{VI.- SEXTA CAUSAL: PREDIOS RUSTICOS PERTENECIENTES $\boldsymbol{A}$ COMUNIDADES.}

1.-Principio general.

2.- Plazo que tienen las comunidades para dividirse.

3.-Excepciones.

\section{1.- Principio General.}

El Proyecto de Reforma Agraria declara expropiables los predios rústicos de que sean dueñas dos o más personas en común respecto de los cuales no se hubiere puesto término al estado de indivisión en los casos, forma y plazo establecidos en la presente ley. 


\section{2.- Plazo que tienen las comunidades para dividirse.}

Las comunidades en que existan predios rústicos deberón dividirse dentro del plazo de dos años a contar de la fecha de la vigencia de la ley. Cuando el hecho que origina la comunidad sea posterior a esa fecha, el plazo de dos años se contará desde el nacimiento de la comunidad, salvo que ésta se deba a sucesión por causa de muerte o disolución de sociedad conyugal. En este último caso no se señala término para la división.

Los pactos de indivisión celebrados no tendrán efecto en cuanto $a$ los predios rústicos comprendidos en la comunidad y tampoco lo tendrón los que se celebren en lo sucesivo. Todo comunero puede pedir en cualquier momento la partición.

En el caso de las comunidades existentes a la fecha de vigencia de la ley, el plazo será de dos años a contar desde la promulgación de la misma.

\section{3.- Excepciones.}

La causal de expropiación que estamos examinando no se aplica a las comunidades agrícolas de las Provincias de Coquimbo y Atacama, ni a las tierras comunes indígenas, ni a las comunidades constituídas según decreto ley 153, de 1932, ni a aquellas comunidades tradicionales que determine el Presidente de la República por decreto supremo dictado en el plazo de 180 días contódos desde la vigencia de la Ley de Reforma Agraria, ni a las tierras que se asignen en copropiedad poir la Corporación de la Reforma Agraria.

El plazo que tienen las comunidades para dividirse no se aplica a las comunidơdes que recién hemos enumerado, ni a lass que posean en "dominio terrenos de aptitud exclusivamente forestal o terrenos agrícolas no arables, cuando unos u otros estén cubiertos de bosques artificiales o de bosques naturales sometidos a un plan de ordenación aprobado por el Ministerio de Agricultura.

\section{VII.- SEPTIMA CAUSAL: PREDIOS RUSTICOS UBICADOS EN LA ZONA DE APLICACION DE LA LEY DE PROPIEDAD AUSTRAL.}

"El proyecto de reforma agraria del Presidente Frei declara de utilidad pública y autoriza la expropiación de "los predios rústicos ubicados en la zona de aplicación de la Ley de la Propiedad Austral donde se hayan producido cuestiones legales relacionadás con el dominio o posesión de la tierra".

Esta disposición del proyecto ha provocado injustificada alarma.

¿Es una novedad en la legislación chilena este motivo de expropiación? No, en absoluto. Existe desde el 24 de Diciembre de 1943, fecha de publicación de la Ley No 7.747. Se incorporó a la Ley No 15.020, bajo el gobierno del Presidente Jorge Alessandri, para someterla al régimen que esa ley establece. El proyecto de reforma agraria lo único que hace es repetirla textualmente de las leyes anteriores, con el fin de sujetarla a las nuevas normas de procedimiento y pago.

La causal en estudio la ha aplicado el Ministro de Tierras y Colonización. desde el año 1943, sin que se hubiere producido ninguna de las catástrofes que se auguran $\mathrm{y}$ sin que se hubiese protestado por la existencia de una 
Institución que hoy encuentra inaceptable.

Explicamos la situación. Desde BíoBío hasta Aysén la constitución de la propiedad ha sido irregular. Muchas leyes de prohibiciones que afectaron a los indígenas no fueron respetadas; asimismo, muchas tierras del Estado han sido usurpadas. Ante estos hechos se dictaron las leyes de la propiedad austral, cuyo texto está contenido en el Decreto Supremo 1600, de 1931 y cuya finalidad es delimitar la propiedad fiscal de la particular.

Pues bien, en muchos casos, por errores de hecho ocurridos en anteriores Administraciones, especialmente entre los años 1930 y 1940, se reconocieron como válidos frente al Fisco títulos sobre terrenos en que el peticionario no tenía posesión material $\mathrm{y}$, por el contrario, estas tierras eran ocupadas y cultivadas por esforzados colonos. La expropiación tiene por objeto salvar los errores mencionados, Y nada más. Hay colonos que esperan hace más de 30 años que se repare esta injusticia.

La Jurisprudencia de la Contraloría General de la República y de los Tribunales de Justicia han fijado el alcance de la causal que comentamos $y$, en la forma en que estos organismos la han interpretado, se ha aplicado invariablemente hasta la fecha. Para que sea posible expropiar en virtud de ella deben existir en las tierras ocupantes con anterioridad al reconocimiento de validez de los títulos y debe tratarse de colonos que no tengan vínculo contractual alguno con el propietario. Como puede verse su acción es muy limitada y todos los agricultores del sur, nacionales o extranjeros, que trabajan sus tierras y que no tengan en ellas ocupantes con anterioridad al reconocimiento de vall- dez de los títulos, nada tienen que temer porque la causal no les afecta $y$ porque aunque algunos lo duden, nos encontramos en un régimen de derecho.

Las observaciones hechas sobre esto punto no tienen fundamento sólido."

Francisco Cumplido

\section{VIII-- OCTAVA CAUSAL: PRE- DIOS RUSTICOS QUE SE ENCUEN- TREN COMPRENDIDOS DENTRO DE UN AREA DE RIEGO.}

"El proyecto de reforma agraria del Presidente Frei declara de utilidad pública y autoriza la expropiación de los predios comprendidos dentro de un área en la que el Estado esté realizando o vaya a realizar obras de riego o de mejoramiento de riego.

Corresponde al Presidente de la República establecer áreas de riego mediante un Decreto Supremo que apruebe para ellas un plan de desarrollo agropecuario.

Esta causal de expropiación ya existía en la ley $N^{\circ} 5.604$ de 16 de Febrero de 1935 (Art. 21 del texto definitivo D.F.L. 76 de 1960), que prescribía la expropiabilidad de hasta la tercera parte de los terrenos que se rieguen por medio de las obras que se ejecuten por el Estado. La Ley Número 15.020 la incorporó en su Art. 15, letra b), pero ya permitió la expropiación de hasta la mitad de los terrenos regados.

La experiencia en relación con el pago de las obras de riego ejecutadas por el Estado es francamente desalentadora. En efecto, la falta de recepción de las obras definitivas por parte de los beneficiarios de ellas ha impedido que el Fisco recupere oportunamente 
las inversiones y un gran número de regantes han visto aumentar el valor de sus predios en forma considerable a expensas de toda la comunidad, sin que exista un sistema adecuado de pago de las obras.

La expropiación consagrada en las leyes N.os 5.604 y 15.020 es un tanto arbitraria, pues estó limitada a una tercera parte de los terrenos en la primera, y a la mitad en la segunda. ¿Por qué un tercio o un medio y no dos tercios, tres cuartos, etc?

El proyecto de reforma agraria que examinamos consagra el pago de las obras de riego en tierras. Así se cumplen íntegramente los fines de la reforma. Por una parte, el propietario de los terrenos, que los explota a lo menos directamente, se beneficia con el plan de desarrollo agropecuario y mantiene en su dominio tierras regadas o mejoradas en su seguridad de riego, y por otra parte, el sacrificio de la comunidad se ve compensado con un pago oportuno en terrenos disponibles para distribuirlos entre los campesinos, arrendatarios $\mathrm{y}$ minifundistas.

El sistema opera en la siguiente forma. Declarada el área de riego y aprobado el plan de desarrollo agropecuario se efectúan las expropiaciones. El propietario que sea persona natural y que explote directamente su predio y las sociedades de personas que cumplan los requisitos que establece el proyecto, tienen derecho a conservar en su dominio terrenos que, una vez terminadas las obras de riego, tengon un valor equivalente al que tenía su predio a la fecha de la expropiación y hasta el máximo socialmente conveniente (80 Hás. de riego básicas). Además si se trata de un óptimo empresario agrícola, que ya tuviere terrenos regados, tiene derecho a hacer efectiva su reserva en los terrenos regados y a conservar en su dominio hasta 320 Hás. de riego básicas.

El proyecto establece un sistema que permite al propietario saber anticipadamente cuáles de sus terrenos formarán parte de los que, en definitiva, una vez terminadas las obras de riego, va a mantener en su dominio.

Ejecutadas las obras se fija el valor de las tierras regadas. Sólo una parte del costo de las obras será de cargo de los regantes, pues hay que distribuir los gastos entre los diferentes usuarios de las aguas: agricultra, industria, electricidad, turismo, parte que obsorberá el Estado, etc. Lógico es, además, que los propietarios no paguen un valor superior al beneficio que reciben por dichas obras. Estas son por su detalle materias propias de un Reglamento que el Presidente de la República deberá dictar dentro del plazo de 180 días, contados desde la vigencia de la Ley.

Ahora bien, determinado el valor de los terrenos regados se reajusta el que el predio tenía a la fecha de la expropiación, para comparar estimaciones equivalentes; del valor del predio reajustado se resta o detrae el de los terrenos regados que el propietario conserva en su dominio. La diferencia es el monto de la indemnización que debe recibir el propietario en la forma que la Ley establece. Por ejemplo, suponiendo que el valor del predio a la fecha de la expropiación era de quinientos mil escudos, que durante los cinco años que demoró la ejecución de las obras el índice de reajuste varió en un 50 por ciento y que la hectárea vale $E^{\circ} 3.000$, se procede en la siguiente forma: Valor del predio reajustado $E^{\circ} 750.000$ menos valor de los terrenos regados que el propietario conserva en su dominio ( $E^{\circ} 3.000$ por 
80 es rgual E $E^{9} 240.000$ ) resulta una indemnización de $E^{\circ} 510.000$ a forvor del propietario".

Francisco Cumplido.

IX:- NOVENA CAUSAL: SON EXPROPLABLES LOS PREDIOS RUSTICOS QUE CONSTITUYEN MINIFUNDIOS.

El Proyecto de ley de Reforma Agraria declara expropiables, asimismo, los predios rústicos que constituyan minifundios, para el sólo efecto de reagruparlos $\mathrm{Y}$ asignarlos en unidades familiares. Tendrán preferencia para ser asignatarios de dichas unidades los ex propietarios que muestren mejor capacidad para el trabajo del campo.

Cabe recordar que el artículo $1^{\circ}$ de la ley define al minifundio como "todo predio rútisco que no alcance a constituir una unidad agrícola familiar $\mathrm{y}$ también aquellos terrenos pertenecientes a comunidades en las cuales el número de comuneros sea manifiestamente superior a la capacidad del suelo para subvenir, mediante una explotación racional, a la adecuada subsistencia de los respectivos grupos familiares".

\section{X.- DECIMA CAUSAL: SON EX- PROPIABLES LOS PREDIOS RUSTI- COS QUE SEA NECESARIO ADQUI- RIR PARA COMPLETAR UN PRO- GRAMA DE REFORMA AGRARIA.}

También son expropiabls los predios rústicos que sea necesario adquirir para completar un programa de Reforma Agraria y que sean ofrecidos por su dueño a la Corporación. En este caso, la indemnización por la expropiación se pagará con un $10 \%$ al contado $y$ el saldo mediante bonos de la Reforma Agraria de la clase "A".
Conviene recordar que la amortización de los bonos de la Reforma Agraria de la clase " $A$ ", se hace en 25 cuotas anuales.

\section{A P I T U L O III}

I.-Las tierras que pertenecen al propietario óptimo hasta un máximo de 320 hectáreas.

II.-Los predios pertenecientes a personas que se comprometan a realizar en ellos un plan de habilitación de suelo y de explotación racional.

III.- Viñas pertenecientes a empresas vitivinícolas integradas.

IV.-Estaciones Experimentales, Centros de docencia agropecuaria o forestal.

V.-La propiedad familiar agrícola.

VI.-Los bosques artificiales y los bosques naturales acogidos a un Plan de ordenación, cuando uno u otros estén situados en terrenos de aptitud exclusivamente forestal o en terrenos de aptitud agrícola no arables.

I.- SON INEXPROPIABLES LAS TIERRAS QUE PERTENEZCAN A UN PROPIETARIO OPTIMO HASTA UN MAXIMO DE 320 HAS. (Art. 15).

\section{A.- Principio General}

El propietario óptimo tiene derecho a que se excluyan de la expropiación hasta 320 hás. de riego básicas.

\section{B.- - Requisitos.}

Para disfrutar de esta franquicia es menester que se cumplan una serie de condiciones cuyra síntesis es la siguiente: 
1 - Los predios que se expropien deben serlo por exceso de cabida o porque pertenecen a personas jurídicas. Si el predio se expropia por cualquier otra causal, no puede invocarse este derecho especial de reserva.

2.- La persona natural que pretende acogerse a este régimen debe estar explotándolos personalmente.

3.- La persona jurídica que desee ejercer este derecho debe desarrollar actividades cuyo giro principal sea la explotación agrícola o ganadera y que los predios de que se trate no estén explotados por terceros.

4.- Además pana que el propietario pueda acogerse a este régimen de excepción que le permite librar de la expropiación hasta 320 hás., habrá de rendir prueba sobre los siguientes requisitos (Art. 16): a) cultivo del 95\% de la superficie de riego o del $80 \%$ de la de secano; b) explotación del predio en condiciones técnicas superiores al promedio de la comuna en que está situado, en conformidad a las normas que se fijen por reglamento; c) mantenimiento del suelo en buen estado o programas de conservación - recuperación adecuados a juicio del Ministerio de Agricultura; d) régimen de participación de las utilidades a trabajadores; el pago mínimo total anual por remuneraciones equivalente $a 2$ veces el salario mínimo y al sueldo vital de la provincia en relación al número de jornadas y meses trabajados y a la categoría de los trabajadores, y f) icumplir con todas las disposiciones legales en lo que respecta a vivienda campesina, previsión, legislación social y del trabajo, educarción y samidad. El peso de la prueba de los diferentes requisitos corresponde al interesado.

En lo demás, se aplican las normas que ya examinamos en los números $7,8,9,10$ y 11 de la primera causal de expropiación y que inciden en puntos tan importantes como el plazo paIa hacer valer el derecho de inexpropiabilidad. ubicación de los terrenos de la reserva, reclamaciones, caducidad y derechos de aprovechamiento de aguas.

\section{II.- SON INEXPROPIABLES LOS PREDIOS PERTENECIENTES A PERSONAS QUE SE COMPRO- TAN A REALIZAR EN ELLOS UN PLAN DE HABILITACION DE SUELOS Y DE EXPLOTACION RACIONAL.}

\section{Principio General para las personas naturales.}

Conforme al artículo 179 del Proyecto de Reforma Agraria, el Presidente de la República puede declarar inexpropiables terrenos de que sean dueñas personas naturales o varias personas naturales en común, siempre que sus propietarios presenten un plan de inversiones para la habilitación de suelos y su subsecuente racional explotación. Estos planes deben haber sido aprobados por el Ministerio de Agricultura antes de que el Ejecutivo dicte el decreto declarando que tales - cuales superficies quedarán inexpropiables.

En las provincias de Tarapacá, Antofagasta, Atacama, Coquimbo, Chiloé, Aysén o Magallanes, la inexpropiabilidad mencionada podrá referirse también a terrenos afectos $a$ un plan de mejoramiento de suelos aprobado en la misma forma.

\section{Principio General para las personas jurídicas.}

El artículo $18^{\circ}$ del Proyecto faculta 
al Ejecutivo para declarar inexpropiables terrenos de que sean dueñas personas jurídicas, cuya actividad principal sea la explotación agrị́cola o ganadera, con respecto a los cuales sus propietarios presenten un plan de inversiones para la habilitación de suelos y su subsecuente racional explotación.

Estos planes deben ser aprobados por el Ministerio de Agricultura, pero aquí es menester hacer un distingo:

a) Cualquiera que fuere el lugar en que los terrenos estén ubicados, el Ministerio de Agricultura deberá aprobar los planes de habilitación de suelos y su subsecuente racional explotación, siempre que se trate de sociedades de personas en que la dirección de explotación de la totalidad de las tierras de la sociedad se efectúe por uno de los socios, a lo menos; en que ninguno de los socios lo sea de alguna otra sociedard de personas propietarias de predios rústicos; y que la sociedad se haya constituido o declare su existencia por escritura pública, un extracto de la cual deberá inscribirse en el Registro de Comercio y publicarse en el Diario Oficial en la forma y plazo que establezca el Reglamento.

b) Tratándose de terrenos ubicados en las Provincias de Tarapacá, Antofagasta, Coquimbo, Chiloé, Aysén o Magallanes, el Ministerio de Agricultura deberá aprobar los planes de habilitación de suelos y su subsecuente racional explotación, cualquiera que sea la naturaleza jurídica de las sociedades que pretendan obtener la inexpropiabilidad de sus terrenos.

Ahora bien, tratándose de personas jurídicas existentes a la vigencia de la presente ley, la inexpropiabilidad, en este caso, podrá también fundarse en un plan de mejoramiento de suelos aprobado en conformidad a los principios que hemos examinado anteriormente.

\section{III.-SON INEXPROPIABLES L.AS VI- ÑAS. VINIFERAS PERTENECIEN- TES A EMPRESAS VITIVINICO- LASS INTEGRADAS.}

El artículo 18 del Proyecto faculta al Presidente de la República para declarar inexpropiables los terrenos plantados de viñas viníferas más un $20 \%$ para rotación, de que sean dueñas, desde una fecha anterior al 22 de Noviembre de 1965, sociedades anónimas que tengan el carácter de empresas vitivinícolas integradas, siempre que reúnan las siguientes condiciones:

a) Tener un capital propio destinado a las actividades vitivinícolas equivalente, por lo menos, a cuatro veces el avalúo físcal de los terrenos plantados de viñas;

b) Tener a lo menos el $95 \%$ de las viñas viníferas plantadas con variedades de cepa de calidad autorizada por el Ministerio de Acricultura, y

c) Comercializar como vino fino a lo menos el $50 \%$ de la producción de las viñas de la sociedad. Se entenderá cumplido este requisito si, a la época de cada cosecha, la sociedad propietaria tuviere en sus bodegas una existencia de vinos de años anteriores, equivalente a por lo menos el $50 \%$ de su cosecha normal.

d) Que los empleados y obreros de la empresa vitivinícola integrada, con excepción de aquellos que el reglamento determine, sean dueños de a lo menos el $10 \%$ del total de acciones de la sociedad y tengan en el Directorio a lo menos un miembra. 
e) Tratarse de una sociedad anónima que cumpla con lers condiciones del propietario óptimo, condiciones que hemos analizado en el punto 6 de la primera causal de expropiación (Capítulo II) $y$ en el punto 4 de la letra B. del número I de este capítulo III, preceptos que aquí damos por reproducidos.

Para los efectos de la Ley de Reforma Agraria, se entiende ccmo empresa vitivinícola integrada aquella sociedad anónima que, dedicúndose básicamente a la actividad vitivinícola, produzca, elabore, fraccione y comercialice sus vinos bajo sus propias marcas.

\section{IV.- SON INEXPROPIABLES L A S EST ACIONES EXPERIMENT ALES, CENTROS DE CAPACITACION CAMPESINA $Y$ CENTROS DE DOCENCIA AGROPECUARIA $O$ FORESTAL.}

En conformidad al artículo 21 del Proyecto, no son expropiables los predios rústicos destinados a cumplir funciones experimentales, de centro de capacitación campesina o de docencia agropecuaria o forestal, mientras cumplan con estas funciones, las que deberán ser calificadas por el Ministerio de Agricultura y siempre que los respectivos titulares del dominio no persigan fines de lucro con la explotación de dichos predios.

\section{V. - NO ES EXPROPIABLE LA PRO- PIEDAD FAMILIAR AGRICOLA.}

De conformidad con el artículo 21 del Proyecto de Ley de Reforma Agraria, no es expropiable la propiedad familiar agrícola, salvo que se trate de un predio rústico comprendido dentro de un área de riego, caso en el icual prevalecen los preceptos sobre reorganización de la propiedad en dichas áreas.

Es menester tener presente que el artículo 158, de la iniciativa que comentamos, autoriza al Presidente de la República para dictar, dentro del plazo de 180 días, un estatuto sobre la propiedad familiar agrícola.

\section{VI.-SON INEXPROPIABLES L OS BOSQUES ARTIFICIALES Y LOS NATURALES ACOGIDOS A UN PLAN DE ORDENACION.}

En nuestro concepto, la causal más amplia de inexpropiabilidad de therras se encuentra contenida en el artículo 22 del Proyecto, el que dispone:

"No son expropiables por las causales establecidas de esta ley los bosques artificiales, como tampoco aquellos bosques naturales cuyos dueños estuvieron cumpliendo un plan de ordenación aprobado por el Ministerio de Agricultura, cuando uno u otros estén situados en terrenos de aptitud exclusivamente forestal, en los que sus propietarios estén cumpliendo un programa de forestación aprobado por el Ministerio de Agricultura".

Los terrenos forestales que se declaren inexpropiables en virtud del precepto recién transcrito, no se considerarán, en cuanto a su superficie para los efectos de la aplicación de la causal de expropiación que hemos denominado exceso de cabida.

Por otra parte, la superficie de terrenos forestales que se declaran inexpropiables tampoco se iconsideran para la determinación de la superficie que el dueño de un predio expropiado tiene derecho a conservar en su dominio en conformidad al derecho de reserva examinado en el capítulo segundo. 
La cálificación de terrenos de aptitud exclusivamente forestal $y$ de terrenos agrícolas no arables, así como la de bosque artificial o natural, corresponde al Director General de Agricultura y Pezca, del Ministerio de Agricultura.

La amplitud de esta causal de inexpropiabilidad parece más que razonable cuando el país estó tomando conciencia, quizás por primera vez, que la defensa del árbol, de los bosques con que la naturaleza generosamente nos dotara, constituye, más que una tarea nacional, una verdadera necesidad de subsistencia de la nacionalidad. Es de toda evidencia que la explotación irracional de las riquezas forestales, en el pasado, nos está trayendo, en el presente, toda suerte de catástrofes: desaparición de los ríos navegables, embancamiento de puertos, avance de las dunas, falta de raíces en una tierra que sufre violentos movimientos sísmicos cada cinco años, etc., $y$, en el futuro, de no cambiarse la condiciones, Chile podría ser una larga y angosta faja de .... desiertos.

\section{CAPITULO IV}

\section{FINANCIAMIENTO DE LA REFORMA AGRARIA}

I.- Significado del costo.

II.-- Có́lculos del Ministerio de Hcicienda.

\section{I.- Significado del costo.}

El problema del financiamiento de la Reforma Agraria representa tal vez el talón de Aquiles de la iniciativa de los presentes comentarios. En efecto, podemos estar en presencix de un magnífico Proyecto de Ley que cale en lo más hondo de la estructura agraria de nuestro país. Sin embargo, si estas dispociones no van acompañadas de un adecuado apoyo financiero del Estado y de la colectividad, se llegaría al triste estado de las reformas que quedan sólo en el papel oficial.

"Sabemos que una reforma agraria implica un costo económico muy grande y cuando se piensa que el país quiere llevar adelante su programa de vivienda, de educación, de salud $y$ de redistribución de ingresos y $\alpha$ mismo tiempo costear la Reforma Agraria, se podrá comprender el enorme esfurezo que significa para el Gobierno y, sobre todo, para el país entero.

La Reforma Agraria en otros países ha consumido todos los recursos y sus mejores esfuerzos humanos. El país tiene que conprender que realizarla no significa sólo un reparto indiscriminado de tierras, sino sobre todo una inversión humana y social. Por eso un gobierno que está realizando esta reforma, lo menos que puede pedir es un poco de tiempo y un poco de serenidad para poder realizarla de una manera racional y democrática, sin perturbar el proceso productivo.

Por costosa que sea esta Reforma Agraria, más caro resultaría al país postergar esta decisión inevitable $\mathrm{y}$ los que no quieren realizarla dentro del ambiente democrático, mañana tendrían que sufrirla en la violencia $y$ el desorden como les ha ocurrido $a$ muchas otras naciones. Pido para ello la cooperación de los agricultores para que comprendan, ayuden $\mathrm{y}$ no se dejen engañar por falsas informaciones". (1)

1) Mensaje Presidencial del 21 de Mayo de 1966, página 26. 
Por otra parte, conociendo los volúmenes presupuestarios con que se piensa afrontar el proceso de reforma, es posible calcular, en forma aproximada, la velocidad y profundidad con que se llevarón adelante las expropiaciones.

\section{II.- Cálculos del Ministro de Hacien- da.}

Hacer vaticinios en cuanta al número de predios que se expropiarón $y$ al número de familias campesinas que obtendrón en dominio tierras de la Reforma Agraria constituye uno de los aspectos más comentados $\mathrm{y}, \alpha \mathrm{l}$ mismo tiempo, más polémicos. Por nuestra parte, corriendo el riesgo que se nos tache de parciales, estimamos que para pronunciarse sobre cómo se proyecta financiar el costo de la reforma la voz más autorizada es la del Señor Ministro de Hacienda $y$, en tal sentido, reproducimos las declaraciones por formuladas en la Comisión de Hacienda de la $\mathrm{H}$. Cámara de Diputados el día Viernes 13 de Mayo de 1966 y cuyo texto es el siguiente:

"Sobre la base de promedios ponderados de valores determinados para ocho casos típicos de unidades agrícolas familiares, se llegó a un costo total para la instalación de una familia ascendente a $E^{\circ}$ 40.250.compuesto en la siguiente forma:

\begin{tabular}{|c|c|}
\hline \multicolumn{2}{|l|}{ 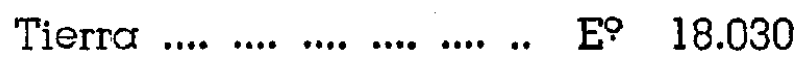 } \\
\hline Infraestructura $\ldots . . . . . .$. & 10.790 \\
\hline Capital de explotación & 6.300 \\
\hline Capital circulante .... .. & 3.100 \\
\hline Puesta en marcha .... .... & 2.030 \\
\hline
\end{tabular}

Esta suma total de E: 40.250.- se gasta en el curso de veinticinco años. Así, por ejemplo, del valor de la tierra se gasta solamente un diez por ciento al contado, o menos y la infraestructura tiene, también, un período de inversión que se ha calculado en cinco años. Por otra parte, debe considerarse, igualmente, un período inicial de tres a cuatro años sin recuperaciones, pasado el cual, el monto de aquellas es superior a los gastos que es necesario seguir haciendo, por lo que quedará un excedente neto.

Para completar el proceso de reforma rspecto de cien mil familias, consideradas ya las dos mil que se incorporaron en el año 1965, se contempla el siguiente ritmo:

\begin{tabular}{ccc}
\hline Año & $\begin{array}{c}\text { No de familias } \\
\text { asentadas }\end{array}$ & $\begin{array}{c}\text { No acumulado } \\
\text { de tamilias }\end{array}$ \\
\hline 1966 & 4.000 & 4.000 \\
1967 & 9.000 & 13.000 \\
1968 & 12.000 & 25.000 \\
1969 & 15.000 & 40.000 \\
1970 & 18.000 & 58.000 \\
1971 & 20.000 & 78.000 \\
1972 & 20.000 & 98.000 \\
\hline
\end{tabular}

Sobre la base de las cifras dadas y considerado el ritmo de progreso, el saldo por financiar por cada unidad agrícola familiar es, en el primer año, de formación del asentamiento, de $E^{\text {? }}$ 11.860.- el segundo año de E 3.860 , el tercer año, de asignación de las unidades, de E 5.700 y el cuarto año, de $E^{\circ} 460$. - con un total para estos cuatro años de $E^{\circ} 21.880$.

Para la estimación del costo del programa, en lo que se reflere a la 
tierra, se consideró el pago al contado de un $10 \%$ y el saldo en veinticinco años, como se ha dicho, más un 3\% de interés. Por su parte, el asignatario paga un $2 \%$ al contado y el saldo, también, a veinticinco años plazo, con $3 \%$ de interés.

Respecto de la infraestructura, se estima la reparación de la mitad de las casas, correspondiendo un $25 \%$ al primer año y otro $25 \%$ al segundo; la otra mitad deberá construirse en el término de cuatro años, con sólo un $5 \%$ el primer y segundo año, y un $25 \%$ el tercero, para completarse con un $15 \%$ en el cuarto año. La construcción de galpones se completa en cuatro años con $10 \%$ en el primero y segundo, $50 \%$ en el tercero y $30 \%$ en el cuarto. La construcción de edificios comunes se hará en los dos primeros años: un diez por ciento en el primero $y$ el resto en el segundo. La construcción de cercos se haría por mitades en el tercero y cuarto años. La construcción de caminos en los tres años, con un $20 \%$ en el primero, un $40 \%$ en el segundo y otro $40 \%$ en el tercero. Se contemplan obras de mejoramiento general también en los tres primeros años y la instalación de agua potable y alcantarillado en el tercero y cuarto, así como la de luz eléctrica, por mitades en el cuarto $y$ quinto.

La Corporación aportará en cada año agrícola la totalidad del capital necesario para operar las sociedades de asentamiento, recuperándolo al final de cada año, con el diez por ciento le las utilidades que se obtengan de la explotación. Asimismo, otorgará a los asignatarios un crédito inicial para que adquieran su capital de explotación y créditos anuales durante diez años para financiar sus necesidades de capital circulante en proporciones sucesivamente decrecientes. El primero de estos créditos será pagado por sus beneficiarios en cuatro $\mathrm{y}$ en diez años, según los casos, y el segundo al final del año agrícola, más un $4 \%$ de interés.

Para poner en marcha los proyectos será necesario contar con un jefe de proyecto por cada doscientas a cuatrocientas familias, un auxiliar por cada treinta a cincuenta familias y un vehículo por cada treinta a cien familias.

Para poder hacer las 98.000 unidades con el ritmo ya señalado, será necesario la siguiente inversión anual durante el decenio 1966-1975, (en miles de escudos de 1965):

\begin{tabular}{lrrrrrr}
\hline \hline Año & Tierra & $\begin{array}{c}\text { Infraes- } \\
\text { tructura }\end{array}$ & $\begin{array}{c}\text { Aportes } \\
\text { a los } \\
\text { Asenta- } \\
\text { mientos }\end{array}$ & $\begin{array}{c}\text { Crédito a los } \\
\text { asignatarios }\end{array}$ & $\begin{array}{c}\text { Puesta } \\
\text { en marcha }\end{array}$ & $\begin{array}{c}\text { GASTO } \\
\text { TOTAL }\end{array}$ \\
\hline 1966 & 7.200 & 5.460 & 31.220 & - & 2.820 & 46.680 \\
1967 & 18.870 & 21.720 & 108.200 & - & 8.170 & 156.960 \\
1968 & 30.360 & 54.640 & 179.100 & 37.600 & 14.380 & 316.080 \\
1969 & 44.020 & 96.720 & 231.000 & 95.760 & 21.960 & 489.460 \\
1970 & 59.910 & 135.360 & 282.900 & 147.830 & 29.080 & 655.080 \\
1971 & 76.500 & 167.950 & 327.000 & 205.480 & 34.580 & 811.510 \\
1972 & 91.050 & 196.230 & 346.000 & 267.780 & 38.220 & 939.280 \\
1973 & 69.790 & 190.180 & 190.000 & 324.400 & 26.390 & 800.760 \\
1974 & 71.710 & 146.090 & - & 362.220 & 18.200 & 598.220 \\
1975 & 73.620 & 59.320 & - & 205.840 & 9.100 & 347.880 \\
\hline
\end{tabular}


La composición porcentual de este gasto es la siguiente:

\begin{tabular}{lllllll}
\hline Año & Tierra & $\begin{array}{c}\text { Infraes- } \\
\text { tructura }\end{array}$ & $\begin{array}{c}\text { Aportes } \\
\text { a los } \\
\text { Asent. }\end{array}$ & $\begin{array}{c}\text { Crédito a los } \\
\text { asignatarios }\end{array}$ & $\begin{array}{c}\text { Puesta } \\
\text { en marcha }\end{array}$ & $\begin{array}{c}\text { GASTO } \\
\text { TOTAL }\end{array}$ \\
\hline 1966 & 15,4 & 11,7 & 66,8 & - & 6,1 & 100,0 \\
1967 & 12,0 & 13,8 & 69,0 & - & 5,2 & 100,0 \\
1968 & 9,6 & 17,3 & 56,7 & 11,9 & 4,5 & 100,0 \\
1969 & 9,0 & 19,7 & 47,2 & 19,5 & 4,5 & 100,0 \\
1970 & 9,1 & 20,7 & 43,2 & 22,6 & 4,4 & 100,0 \\
1971 & 9,4 & 20,7 & 40,3 & 25,3 & 4,3 & 100,0 \\
1972 & 9,7 & 20,9 & 36,8 & 28,5 & 4,1 & 100,0 \\
1973 & 8,7 & 23,8 & 23,7 & 40,5 & 3,3 & 100,0 \\
1974 & 12,0 & 24,4 & - & 60,5 & 3,0 & 100,0 \\
1975 & 21,2 & 17,0 & - & 59,2 & 2,6 & 100,0 \\
\hline
\end{tabular}

El financiamiento del gasto que implicará el proceso de Reforma Agraria es el siguiente:

\section{RECUPERACIONES}

Año $\quad \begin{gathered}\text { Gasto } \\ \text { Total }\end{gathered}$

\begin{tabular}{lc} 
Retiros & $\begin{array}{c}\text { Amorti- } \\
\text { de los } \\
\text { zación } \\
\text { de cré. } \\
\text { mienta- } \\
\text { ditos }\end{array}$ \\
\hline
\end{tabular}

\begin{tabular}{rrrr}
1966 & 46.680 & - & \multicolumn{1}{c}{-} \\
1967 & 156.960 & 33.080 & \multicolumn{1}{c}{-} \\
1968 & 316.080 & 114.720 & 1.440 \\
1969 & 489.460 & 190.000 & 18.550 \\
1970 & 655.080 & 245.130 & 57.550 \\
1971 & 811.510 & 300.220 & 111.970 \\
1972 & 939.280 & 347.130 & 179.990 \\
1973 & 800.760 & 367.540 & 261.140 \\
1974 & 598.220 & 201.800 & 346.680 \\
1975 & 347.880 & - & 419.470
\end{tabular}

Costo total en el quinquenio 1966-1970

Costo total del programa
GASTOS YA INCLUIDOS

EN OTROS PROGRAMAS a/
Necesidad de ciamiento a/

a/ Falta por incluir las inversiones en riego y los créditos que están recibiendo actualmente de instituciones públicas los predios que serán expropiados, lo que reduce las necesidades de nuevo financiamiento.

Debe recalcarse que este nuevo fi- cuperados en los años siguientes, al nanciamiento, es sólo una colocación, amortizar sus deudas los asignatarios. ya que esos fondos son totalmente re- Cabe destacar, como está indicado 
en el cuadro, que dos de los rubros corresponden a costos actuales de los Ministerios de la Vivienda y de Obras Públicas, o sea, las inversiones en habitación y caminos, y forman parte de los programas ordinarios de inversiones de capital del Estado.

Según explicó el señor Ministro, la diferencia entre el financiamiento $a$ base de la emisión de bonos y el costo anual real de la inversión deberá ser consultada anualmente en la Ley de Presupuesto de Gastos de la Nación, para lo cual, como se ha dicho, la Comisión acordó agregar un artículo nuevo que así lo dispone expresamente. El estudio expuesto son las metas que se consideran factibles y la prioridad deberá otorgarla el Ejecutivo mediante el mecanismo presupuestario como órgano de planeamiento $\alpha$ corto plazo.

Por lo que respecta a la capacidad de pago de los asignatarios, ella ha sido calculada sobre la base de estudios practicados principalmente por la Corporación de la Reforma Agraria, que atribuyen una utilidad neta de seis mil escudos en el año a cada uno".

(Continuará)

Santiago, Junio de 1966. 